\title{
La Celestina en la transición. Censura, polémica e interpretación de la recreación telefílmica de Juan Guerrero Zamora ${ }^{1}$
}

\author{
José Eduardo Villalobos Graillet \\ University of Toronto
}

\section{RESUMEN}

El artículo se propone examinar, en primer lugar, los problemas que atravesó el guion de la recreación cinematográfica basada en La Celestina de Juan Guerrero Zamora durante el franquismo. Para ello, se analiza el expediente de censura depositado actualmente en el Archivo General de la Administración (Alcalá de Henares). En segundo, la polémica que se generó en los periódicos españoles cuando el proyecto finalmente llegó a producirse para la televisión en la etapa de la transición hacia la democracia. Como se mencionará, parte de ello se debió a que en ese entonces TVE buscaba crear una nueva imagen de anticorrupción en los telespectadores e, indirectamente, provocar la salida del realizador del medio. Y, por último, el tratamiento libre y personalizado que el director dio a la adaptación de esta obra clásica..

Palabras Clave: Juan Guerrero Zamora, censura, TVE, adaptación, transición a la democracia.

\section{La Celestina in the Transición. Censorship, polemic, and interpretation of the TV adaptation by Juan Guerrero Zamora}

\section{ABSTRACT}

This article examines, firstly, the difficulties that La Celestina-based film script by Juan Guerrero Zamora went through during Franco's dictatorship. To this end, I study the censorship files stored at the General Archive Administration in Alcalá de Henares. Secondly, the controversy that was generated in Spanish newspapers when this project finally came to be produced for the television in the transition to democracy era. As I will mention, part of this uproar was because at that time the Spanish Television Network sought to create an anti-corruption image in viewers and, indirectly, to make Guerrero Zamora leave the company. Lastly, the free and personal treatment that this director gave in adapting this classic book.

KeY words: Juan Guerrero Zamora, censorship, Spanish Television Network, adaptation, transition to democracy.

1.- Agradezco a la Facultad de Artes y Ciencias de la Universidad de Toronto por apoyar con sus fondos este proyecto de investigación. De la misma forma, agradezco a la actriz Alejandra Torray, hija de Juan Guerrero Zamora y Nuria Torray, por concederme una entrevista telefónica el día 9 de noviembre de 2018 durante mi estancia en Madrid. 
El llamado concurso de los '1.300 millones de pesetas' promovido por el Ministerio de Cultura en 1979 fue parte significativa del avance que se estaba dando en el modo de realizar ficción televisiva, mismo que continuaría hasta finales de la década de los ochenta gracias al impulso de la economía española. Independientemente de esta iniciativa, pero bajo la misma fórmula estética, TVE venía financiando miniseries de corte literario realizadas por los profesionales de casa sin requerir, en la mayoría de las ocasiones, de la presentación previa de guiones ni mucho menos de avances presupuestarios. Una de ellas fue el telefilm de tres episodios titulado La Celestina del prestigioso Juan Guerrero Zamora (Melilla, 1927). La amplia experiencia de este realizador en los espacios dramáticos del ente público repercutiría positivamente para que los directivos del ente público dieran luz verde a su producción en 1981, a diferencia del proyecto de Julio Diamante al que censuraron tajantemente dos años antes. ${ }^{2}$ No obstante, lo que estas autoridades desconocían fue que el guion del melillense llevaba aproximadamente quince años varado a causa del entramado financiero y la censura cinematográfica de la dictadura.

En el presente trabajo examino, por una parte, el expediente de censura del que habría sido el primer largometraje español basado en la obra de Fernando de Rojas con el fin de exponer las temáticas y el lenguaje que incomodaron a los miembros de la Junta de Censura y Apreciación de Películas. ${ }^{3}$ Como se verá más adelante, en el transcurso de 1965 el director realizaría en su guion las correcciones propuestas por ambas vertientes de la entidad para obtener los beneficios de la categoría de 'Interés Especial'. Sin embargo, pese a que sería autorizado, la condición que impuso dicho organismo, de pasarlo a una segunda evaluación una vez rodado, pudo haber representado un riesgo financiero no solo para el realizador, que era a la vez el guionista y el coproductor del proyecto, sino para la productora Cooperativa CITA Films, puesto que no garantizaba su estreno en las salas comerciales. Como consecuencia, Guerrero Zamora autocensuraría su propuesta hasta encontrar los medios suficientes que TVE facilitaría para llevarlo a cabo en la aún etapa de la transición. Y, por otra parte, analizo la lectura que el director ofreció en los tres episodios emitidos en 1983, la cual irónicamente no ha sido valorada por los académicos celestinescos debido a que han centrado su atención en la polémica sobre los altos costos y los casi dos años en que demoró su producción.

La adaptación cinematográfica de este clásico de la literatura española fue uno de los sueños dorados del teleasta Juan Guerrero Zamora que empezó a confeccionar en 1964 (Yale 1965: s.p.). Esta intención la haría

2.- En otro artículo que está por publicarse examino los motivos que llevaron a Televisión Española a censurar el guion del telefilm basado en La Celestina que Julio Diamante presentó en el mencionado concurso de 1979.

3.- Expedientes 108-65 y 108-66, caja 36.0404 del Archivo General de la Administración. 
saber públicamente a la Dirección General de Cinematografía y Teatro el 19 de agosto de ese mismo año cuando presentó un breve resumen argumental del proyecto. Tras varios meses en perfilar y redactar tanto el guion como la ficha técnica y artística, el secretario general de la Cooperativa CITA Films, José Luis González Álvarez, solicitaría a finales de marzo de 1965 la preceptiva autorización del organismo para poder realizar el largometraje. Sin embargo, a los quince días recibiría los informes de los censores y de la Dirección General de Licencias e Inspección prohibiéndolo unánimemente, ya que infringía los apartados $13^{\circ}$ y $18^{\circ}$ de las Normas de censura cinematográfica creadas en $1963 .^{4}$

A saber, la primera causa que llevó a las autoridades a rechazar el guion de Guerrero Zamora fue el uso de expresiones coloquiales y lascivas que hacían que este proyecto de recreación cinematográfica de $L C$ fuera de mal gusto. No muy alejada de esta aseveración, la segunda fue la abundancia de escenas 'escabrosas' consideradas no aptas para el alcance de todo el público, tales como los eventos que ocurren en el burdel de Celestina. A juicio de los censores, el director pretendía con estos aspectos hacer un film no solo para una ordinaria distribución comercial, sino para el consumo por parte de un sector de la sociedad que no era lo suficientemente culto. ${ }^{5}$ Como consecuencia, el crítico de cine Pedro Rodrigo exigiría en la parte final de su informe de censura que el director escribiera otra versión del guion pensando en un lenguaje y en un público más bien cinematográficos, aunque irónicamente reconocía el esfuerzo que este había puesto en crear una adaptación fiel al espíritu y a la letra de la obra de Rojas. ${ }^{6}$

La resolución desfavorable de la junta censora hizo que Guerrero Zamora luchara a toda costa para hacer realidad su proyecto. En poco más de un mes revisaría los elementos del guion antes descritos para presentar una nueva versión de este. José Luis González Álvarez se encargaría de hacérsela llegar a José María García Escudero, Director General de Cinematografía y Teatro, adjuntando también una misiva en la que justificaba el tratamiento que tanto en la versión anterior como en la segunda ofrecían. Asimismo, aprovecharía para solicitar al organismo dirigido por esta autoridad que a la película se le concediera la licencia de rodaje y, al mismo tiempo, fuera distinguida con la categoría de 'Interés Especial'.

Con relación al lenguaje, el secretario de la Cooperativa CITA Films argumentaba en tal documento que el director realizó un estudio profundo

\footnotetext{
4.- «Norma decimotercera. Se prohibirán las expresiones coloquiales y las escenas o planos de carácter íntimo que atenten contra las más elementales normas del buen gusto». "Norma decimoctava. Cuando la acumulación de escenas o planos que en sí mismo no tengan gravedad, cree, por la reiteración un clima lascivo, brutal, grosero o morboso, la película será prohibida» (BOE 1963: 3930).
}

5.- Informe de S.R. firmado el día 14 de abril de 1965.

6.- Informe con fecha del 14 de abril de 1965.

7.- Documento firmado el 17 de mayo de 1966. 
de la sintaxis y el léxico de finales del Medioevo para que los diálogos que había modernizado fueran inteligibles para el público español de la década de los sesenta. Por lo tanto, este desbroce en su propuesta de largometraje no tenía ninguna intención de contradecir el estilo del autor literario ni mucho menos la orientación picaresca de la literatura española de la que los personajes del mundo bajo celestinesco son representantes. En cuanto al ambiente, González Álvarez explica que las secuencias del guion fueron pensadas para aportar belleza plástica y no para resultar ofensivas a los espectadores. De tal modo, según él, el orden estético que ofrecía esta adaptación era más cercano al de Rojas que al de aquellas adaptaciones habituales que acababan desfigurando con anacronismos los textos clásicos en los que estaban basados.

En la primera semana de junio de 1965, la Junta de Censura y Apreciación, así como la Dirección General de Licencias e Inspección desestimarían por igual el guion y la petición del interés especial. ${ }^{8}$ Nuevamente, Pedro Rodrigo mostraría su inconformidad en la presentación de imágenes y diálogos en el proyecto que, si bien eran completamente fieles al contexto de $L C$, seguían siendo escabrosos para la plástica cinematográfica. Específicamente, insistía al director en tamizar, tanto en fondo como en forma, todas las escenas de la taberna en que las prostitutas, los rufianes y otros personajes del mundo bajo se expresan o actúan de modo grosero. Asimismo, la secuencia del cuarto de Areúsa que, aunque Rodrigo no se atreve a describir por pudor, supongo que se trata del momento en que Celestina anima a su protegida a tener relaciones sexuales con Pármeno.

Insatisfecho con tal informe desfavorable, Juan Guerrero Zamora solicitaría personalmente por escrito al Director General de Cinematografía y Teatro la reconsideración de su proyecto el día 28 de junio de 1965. Esto es mediante un examen minucioso del guion para que así pudiera perfilarlo según las recomendaciones de la Junta, en sus dos vertientes, y así hacer posible su largometraje. Sin duda, con esta petición el teleasta expresaba su disponibilidad de realizar los cambios necesarios apegándose a las normas que vigilaban los valores de la sociedad durante la dictadura. No obstante, en la carta pondría de manifiesto su indisposición a tergiversar los elementos o aspectos que eran vitales en una obra canónica de la literatura española, cuyo estudio empezaba a generar interés en los programas oficiales de segunda enseñanza.

Las palabras del director serían tan contundentes para el mismísimo García Escudero y la Junta que dirigía, que pasados dos días tendrían listos los reportes solicitados. La Comisión de Apreciación, encargada de evaluar los aspectos técnicos, artísticos y económicos de los films, autorizaba el guion en sus informes, pero con la condición de cuidar todas las escenas eróticas. Entre ellas se encontraban, sin utilizar los eufemis- 
mos del documento, la secuencia en que Celestina toquetea a Areúsa en su cuarto (54), el juego picante entre las parejas de Areúsa-Pármeno y Elicia-Sempronio en la casa de la alcahueta (44 y 45), así como los planos que mostrarían los senos de Melibea y la entrega (sexual) de los jóvenes nobles (161 y 194). De igual forma, sugería suavizar las secuencias de magia como en la que Claudina, con ayuda del infante Pármeno, aparece quitándole las muelas a un ahorcado (50), así como suprimir tanto la escena íntegra de la taberna (78-83) como las palabras o frases que pudieran resultar inconvenientes para la época. ${ }^{9}$

En el caso de la concesión del interés especial, la Comisión decidiría denegarla por la forma explícita en que se retratan los temas anteriores en detrimento de la labor de adaptación cinematográfica. No obstante, resulta demasiado irónico que dos características que el informe consideraba positivas no fueran sido suficientes como para otorgar dicha clasificación al proyecto. A saber, por un lado, se avalaba la ambición artística del guion por su suficiente contenido temático y respeto al texto fuente. ${ }^{10}$ Y, por otro, se elogiaba la experiencia de Guerrero Zamora en otros terrenos artísticos a pesar de no haberse especializado en la Escuela Oficial de Cine. ${ }^{11}$

El informe de la Comisión de Censura, rama que se ocupaba de valorar los aspectos morales, sociales, educativos o políticos de los proyectos fílmicos, no distaba de lo anteriormente mencionado, aunque añadió otras correcciones relacionadas con tales temáticas. Particularmente, el periodista Carlos Fernández Cuenca, integrante de este comité, ofreció una valoración positiva del guion de Guerrero Zamora al compararlo directamente con la película Celestina $P . . . R$... que acababa de estrenar Carlo Lizzani en Italia. ${ }^{12}$ En su opinión, la adaptación libre del director italiano se había aprovechado del nombre y de la profesión de la protagonista de Fernando de Rojas con el fin de promover la inmoralidad entre los espectadores de ese país. Para contrarrestar tal efecto, Fernández Cuenca creía menester llevar al celuloide una Celestina auténticamente española y con el tono artístico adecuado como el que el realizador melillense había da-

9.- Algunos ejemplos de las expresiones que pidió la Comisión que el director suprimiera en su guion son: «puñetero» (7); «putico» (27); «redondez y forma de los pequeños senos» (17); «Areúsa.- ...me encontrará de par en par» (36); «abrir bragueta» (40); «Areúsa.- ¿Por Pármeno?... Hasta, ¿cómo quieres que me sosiegue, ingrato?» y "Centurio.- ... seguirás doncella seguro... Pues no estará tan mocho» (65); "preñada» (69); "su virtud la llevaste ensartada» (132).

10.- Informe de Marcero Arreita-Jáuregui Alonso firmado el 30 de junio de 1965.

11.- Según la Orden Ministerial del 19 de agosto, no era obligatorio que las personas que ejercieran la profesión de director vinieran titulados por parte de la EOC (BOE 1964: 11462).

12.- Carta firmada el 30 de junio de 1965. 
do a su proyecto. ${ }^{13}$ Por tal motivo, la Comisión lo consideraría merecedor de los beneficios del interés especial.

Por su parte, García Escudero autorizaría el proyecto para mayores de dieciocho años con la recomendación de prohibir las secuencias mágicas de Celestina en su laboratorio, las referencias eróticas y las expresiones más procaces. ${ }^{14}$ En cambio, no veía ningún inconveniente en adaptar los 'temas fuertes' que se remontaban a la tragedia clásica, tales como la prostitución y el suicidio, ya que, según él, empezaban a ser habituales en el teatro y el cine de ese entonces. Con respecto al primero, veía en el guion una reprobación moral clara del comportamiento de Celestina y el de sus muchachas. Y, al segundo, aunque el acto era en sí reprobable, consideraba que había una explicación humana en la conducta de Melibea. En todo caso, el Director General pensaba que lo que los espectadores pudieran encontrar de equívoco en el largometraje sería compensando con la amplia difusión de la que gozaba la obra de Rojas por aquellos años.

En cuanto al 'Interés Especial', el informe muestra que García Escudero dudó en ofrecer al film la totalidad de los beneficios del anticipo del millón a causa de la inexperiencia cinematográfica de Guerrero Zamora, que en ese entonces había hecho solo teatro. Sin embargo, pensando en que con esta condición el proyecto del teleasta no se realizaría, el Director General estaba dispuesto a correr el riesgo de concederle el anticipo subordinado, cuya elevación dependía de la realización de la película. Además de este motivo, García Escudero encontraba en el guion la ambición artística suficiente, precisamente por estar basado en uno de los textos cumbres de la literatura española, así como su evidente empeño comercial. En vista de ello, Ángel Gómez Pinilla, jefe de la sección de licencias e inspección, certificaría el 7 de julio de ese mismo año la autorización de los beneficios de la categoría mencionada de acuerdo con el artículo $3^{\circ}$ y en relación con el Capítulo V de la Orden Ministerial del 19 de agosto de $1964 .{ }^{15}$

Después de los informes anteriores, todo parece indicar que el teleasta entregó una tercera versión de su guion a la Junta de Censura y Apreciación de Películas, puesto que el 14 de julio, Luis Gómez Mesa redactó un nuevo comunicado. En este, solicitaba condicionar la concesión del interés especial a la realización del film porque el proyecto no se adecuaba perfectamente al término 'adaptación'. A saber, para este crítico de ci-

13.- Una década antes, el director de cine franquista José Luis Sáenz de Heredia había expresado a la Junta su temor de que el marxista Lizzani fuera el primero en adaptar La Celestina con fines obscenos y de denuncia. Para mayor información, consúltese el trabajo de Santiago López-Ríos (2014).

14.- Estas comprenden todas las escenas de las diversas parejas que están en casa de Celestina (32, 36, 39 y 40); la secuencia íntegra entre Pármeno y Areúsa (79); las frases «su virtud la llevaste ensartada» (115) y "las manos de él van desabrochando el corpiño de ella hasta que los senos afloran» (141).

15.- Publicadas en el BOE no. 210 del $1^{\circ}$ de septiembre de 1964. 
ne, adaptar La Celestina significaba sintetizar los elementos coloquiales y 'agobiantes' que en el proyecto de Guerrero Zamora eran excesivos. Asimismo, evitar que las secuencias cayeran en lo irreverente en el momento en que se hicieran 'muy cinematográficas' o, en todo caso, explícitas. No obstante, al igual que los otros vocalistas de la Junta, Gómez Mesa reiteraba el esfuerzo que el director había puesto en redactar un guion con cualidades ambiciosas. ${ }^{16}$

La evaluación del crítico de cine pudo haber incidido en el cambio de parecer de García Escudero, ya que a los diez días el dirigente resolvió condicionar la autorización de 'Interés Especial' a la adecuada realización del largometraje según su guion. ${ }^{17}$ En la práctica este hecho significaba, por una parte, que la Cooperativa CITA Films y Juan Guerrero Zamora tenían que sufragar todos los gastos para rodar la película. Y, por otra, que una vez realizada debía pasar por otra revisión de la Junta de Censura y Apreciación, teniendo en cuenta los aspectos que no se habrían recogido en el guion, o bien las circunstancias que pudieran ser debidamente apreciadas durante su visionado. ${ }^{18}$ Por lo tanto, con dicha resolución no se garantizaba que la recreación del teleasta recibiría parcial o totalmente los beneficios de la protección oficial ni mucho menos que la Junta llegaría a autorizar su exhibición, sobre todo porque era sabido que las películas, una vez terminadas, recibían la tijera por parte de este organismo e, incluso, que en algunos casos llegaba a prohibir sus estrenos.

El último documento que aparece adjunto al expediente de censura de este proyecto cinematográfico es el artículo La Celestina, al cine publicado en el periódico Pueblo el 2 de agosto de 1965. En él, según la entrevista que Yale realiza a Guerrero Zamora, se da a conocer públicamente la aprobación de la censura sobre el guion y la clasificación de 'Interés Especial' que le concedieron. No obstante, en este espacio no se llega a anunciar la fecha de inicio de rodaje, aunque se da conocer que una de las actrices, entre las que se encontraba Margarita Xirgu y Ana Magnani, reencarnaría a la vieja alcahueta.

Posterior a esta entrevista recogida en el diario arriba mencionado, ningún otro medio español hablaría más sobre el estatus o el desarrollo del film del melillense. Este hecho podría sugerir que la Cooperativa CITA Films, tras haber analizado los riesgos financieros que habría implicado producir la película conforme a los condicionantes de la Junta, se vio en la tarea difícil de retirar su apoyo al teleasta. Sin poder encontrar ningún productor que financiara su proyecto, Guerrero Zamora aplazaría la rea-

16.- Carta con fecha del 14 de julio de 1965.

17.- Resolución del 24 de julio de 1965.

18.- Además de ello, los productores tenían que cumplir con ciertas obligaciones establecidas en el permiso de rodaje del 24 de julio de 1965, tales como incluir en los títulos del film el nombre de los estudios o de las ciudades españolas en donde se habían grabado las escenas $y$, a su vez, comprobar las inversiones realizadas. 
lización de este hasta que hubiera mejores condiciones en la industria cinematográfica del país. ${ }^{19}$ En vista de ello, retiraría las últimas versiones de su guion del expediente de censura, dejando así abierta la oportunidad a otros profesionistas interesados en adaptar por primera vez al celuloide la obra de Fernando de Rojas. ${ }^{20}$ Sin duda esto no se haría esperar, pues en cuestión de año y medio, Carlos Viudes y Luis Revenga enviarán a la Dirección General de Cinematografía y Teatro el breve resumen argumental de lo que sería un nuevo proyecto fílmico basado en $L C .{ }^{21}$

La frustración que pudo haber dejado la experiencia anterior en Juan Guerrero Zamora, rápidamente la superó con los triunfos que cosechó tanto como realizador como guionista en los ámbitos del teatro y la televisión. ${ }^{22}$ Particularmente, se convertiría en una de las figuras más prominentes de la edad de oro del medio audiovisual a partir del estreno de espacios dramáticos como Gran Estudio, Fila Cero y Estudio 1 (antiguamente conocido como Primera Fila). Estos programas de alto valor cultural no solo serían plataforma de lanzamiento para grandes histriones, sino el género por excelencia que se mantendría por más de tres décadas en ambas cadenas de TVE (Diego 13). A lo largo de este tiempo, el director sería testigo del mejoramiento de las condiciones de producción o del modo de hacer televisión en Prado del Rey. De igual forma, de la evolución de la ficción televisiva, pasando del teatro en vivo al grabado, o de las adaptaciones de novelas a las series dramáticas y, posteriormente, cuando estas últimas entraron en decadencia a mediados de los setenta, a las miniseries (literarias, biográficas y originales). ${ }^{23}$

En esta última etapa de la historia de la ficción en TVE, el teleasta retomaría su guion autocensurado de $L C$ justo después de realizar la miniserie de trece capítulos intitulada Un mito llamado... o también conocida con el subtítulo de Los mitos (1979) con Nuria Torray como protagonista. ${ }^{24}$ A

19.- Así lo confirma el realizador en la entrevista que García Garzón le hizo en 1983 en el diario $A B C$ (1983: 91).

20.- A fecha de hoy se desconoce dónde están depositados el guion definitivo de este proyecto y sus versiones anteriores.

21.- Actualmente me encuentro realizando un estudio sobre este proyecto cinematográfico también censurado durante el franquismo.

22.- Tan solo en esa década recibiría premios como el Nacional de Teatro por los primeros tres tomos de su Historia del Teatro Contemporáneo (1962); el Ondas como Mejor Director (1962); el Nacional de Realización (1967); la Medalla de Oro del Festival de Milán (1969); el Quijote de Oro de la Crítica al Mejor Director (1969-70); y la Antena de Oro de Adaptaciones (1970) (Bravo Nieto 2009: 80; Casesmeiro Roger 2017: s.p.).

23.- Consúltense los estudios de Palacio (2001), García Castro (2002) y Diego (2010) sobre la historia de los espacios dramáticos de TVE.

24.- Tras la auditoría realizada por el Ministerio de Hacienda en RTVE por su mala gestión empresarial-económica, esta miniserie estuvo también envuelta en una polémica sobre su presupuesto, el tiempo de rodaje y la elección de la pareja sentimental del teleasta como la principal intérprete de los episodios. Por si esto fuera poco, el entonces directivo del ente 
mi juicio, la abolición legislativa de la censura cinematográfica, pero, sobre todo las facilidades que ofrecía el ente durante la transición a los productores de casa fueron propicias para que esta recreación finalmente se llevara a cabo en formato de telefilm. A saber, a principios de los ochenta, esta institución pública aprobaba proyectos sin mayores obstáculos, pues solo bastaba presentar una idea vaga y el título de estos o, en todo caso, confiar previamente en el nombre de profesionales consolidados y en los apoyos técnicos o económicos con los que contaban (Palacio 2012: 295). Como si esto fuera poco, el ente no exigía calidad a los proyectos ni mucho menos penalizaba a quienes no cumplieran con ciertos estándares una vez producidos (296).

Sin duda alguna, estos dos últimos aspectos tendrían repercusiones en la recepción de programas de televisión. Específicamente, los críticos echarían en cara al medio la falta de producciones propias o ajenas que fueran tanto creativas como dotadas de calidad. Uno de ellos sería Pablo Corbalán, colaborador del diario $A B C$, quien incluso creía que tales problemas se resolverían, en primer lugar, con la incorporación al ente de más de 400 profesionales de otras áreas en 1981 (1981a: 93). Y, en segundo, con la realización de adaptaciones de textos clásicos o contemporáneos de la literatura española, cuyos objetivos también incluía el de combatir el americanismo que el medio radiofónico y televisivo venían padeciendo (1981b: 92). Para el periodista, el anuncio en julio de ese año de las versiones de La Celestina de Rafael Pujol para Radio Cadena Española (RCE) y de la Tragicomedia de Calixto y Melibea de Juan Guerrero Zamora para TVE serían ejemplos de este gran esfuerzo.

En el caso del segundo proyecto, Corbalán confiaba plenamente en el talento y la experiencia del director melillense para hacer de esta obra canónica una superproducción para la televisión. Sin embargo, consideraba que había dos retos principales que Guerrero Zamora tenía que afrontar para hacer una versión distinta de las que existían hasta ese entonces en el ámbito del teatro y del cine. El primero de ellos era enfocar la trama en la crisis social que se dio durante el tránsito del Medioevo al Renacimiento español en vez de serializarla únicamente como una historia de amor entre Calisto y Melibea. El segundo reto era ofrecer por primera vez una lectura crítica de las circunstancias que bullen a lo largo de la Tragicomedia, pues, según él, las recreaciones anteriores no se atrevieron a hacerlo (92).

Pese a las expectativas que generaría el anuncio de la miniserie de $\mathrm{La}$ Celestina, en noviembre de 1981, Manuel Calvo Hernando suspendería la producción. Según un reporte que Carlos Robles Piquer publica en 1982, las causas que llevaron al nuevo director de la entidad a tomar dicha deci-

programó la serie a una hora de menor audiencia debido a que la consideraba 'demasiado intelectual'. Al respecto, consúltense las «Puntualizaciones de Juan Guerrero Zamora» (1980), el trabajo de Peña Ardid (2010) y el artículo de Casesmeiro Roger (2017). 
sión fueron el incumplimiento tanto de sus plazos presupuestarios como el de su término de realización que estaba contemplado para agosto. ${ }^{25} \mathrm{~A}$ saber, por aquella fecha el ente público le había entregado al teleasta la cantidad de 118.473.204 de pesetas para los tres capítulos de su telefilm de cincuenta y siete minutos de duración cada uno, siendo que el presupuesto inicial había sido de 70.308.496 de pesetas. Del mismo modo, no se había rodado ni un tercio del guion, por lo que faltaban 87 páginas que cubrir (citado en "La estafa» 1982: 44).

A principios del nuevo año, la dirección de TVE estudiaría otras alternativas para completar de una vez por todas dicho proyecto, esto teniendo en cuenta, por un lado, el hecho de no considerar perdida la gran cantidad de dinero para su producción. Y, por otro, que era imposible cambiar de realizador u oponerse a sus órdenes, dado que el contrato que este había firmado con Miguel Ángel Toledano, antecesor de Calvo Hernando, estipulaba que tendría los derechos de propiedad intelectual como guionista y director de la serie. Así pues, el 24 de junio de 1982, tras una primera negativa de Guerrero Zamora, el ente público firmaría un nuevo contrato con él y la empresa Filmes 77, S.A. de la que era propietario, para acelerar la producción y así llevar a buen puerto la serie ("Entrevista personal a Alejandra Torray»).

De tal manera, TVE abonaría 61.057.641 de pesetas a la cantidad ya invertida e, igualmente, acordaría nuevas cláusulas en dicho documento. Entre estas se encontraba la reducción de algunos porcentajes de beneficio del director, el uso de un aval bancario que aseguraba al ente la finalización total del telefilm y la penalización a Guerrero Zamora por cada día de demora en el rodaje (44). ${ }^{26}$ Sin más tardar, el 15 de agosto, el teleasta culminaría el proyecto con fecha tentativa de estreno en el invierno de ese mismo año ${ }^{27}$. Sin embargo, la emisión se programaría hasta octubre del año siguiente en el horario estelar de TVE-1 a causa de otras irregularidades que saldrían a la luz, convirtiéndose así en una de las series más polémicas de $1983 .{ }^{28}$

Desde la contemporaneidad, considero la controversia que rodeó la serie de $L C$ como parte de las tantas denuncias que se hicieron sobre la mala gestión empresarial, así como la corrupción económica e ideológica que eran comunes en el ente. A saber, desde 1977 y, posteriormente, con la auditoría del Ministerio de Hacienda a TVE en 1979, en este y en otros

25.- De acuerdo con Palacio, otra polémica que el director enfrentó en TVE, anterior a Los mitos y a $L C$, estuvo relacionada con el incremento significativo del presupuesto inicial de su telefilm Fuenteovejuna de 1970, pero estrenada hasta 1975 (2012: 67).

26.- Según Robles Piquer, esta cláusula no estaba estipulada en el primer contrato entre Toledano y Guerrero Zamora (citado en "La estafa»1982: 44).

27.- Así se anunciaría el 15 de octubre de 1982 en el diario ABC ("La Celestina»1982: 101).

28.- La serie de seis capítulos dirigida por Mario Camus, Los desastres de la guerra, fue otro de los desfalcos de 1983 por su gran costo que alcanzó las 292.500 .000 de pesetas. 
medios de comunicación se venía recriminando el despilfarro de los fondos de las arcas televisivas, sobre todo en el ámbito de la producción de programas. ${ }^{29}$ De acuerdo con Pérez Ornia, esto fue en gran parte resultado de las 'facilidades' que el organismo ofrecía a los profesionales de plantilla, pues nunca se llegaba a saber con antelación el contenido de los proyectos ni tampoco se estudiaban previamente los costes o la racionalización del material técnico y de personal que se emplearían en los mismos (1988: 418). Como consecuencia de esta insuficiente planificación y de la mala inversión del dinero público, la imagen de la entidad se fue deteriorando paulatinamente entre el colectivo español.

A mi parecer, con el triunfo del Partido Socialista Obrero Español (PSOE) en las elecciones generales de 1982, este tipo de escándalos sirvió como una de sus estrategias para convencer a la sociedad de que en esta nueva época en la televisión no se toleraría ningún caso de corrupción por parte de sus directivos y profesionales. Si bien esta medida mostraba cierto esfuerzo en querer reformar el ente con los valores de la democracia, es de mi opinión que este aún continuaba bajo el control dictatorial del Gobierno. Muestra de ello fue la imposición de un carné de este partido político entre el personal de TVE para poder seguir laborando dentro de sus filas. Sin duda, esta politización afectaría por igual a Juan Guerrero Zamora y a su esposa, la actriz Nuria Torray que interpreta a Melibea en la miniserie, ya que ambos habían mostrado, desde la etapa política anterior, su inconformidad en ponerse etiquetas ideológicas para ejercer sus carreras profesionales (García Garzón 1983: 91; Amilibia, 1983a: 83). Como consecuencia, en el ente no solo se les tachó de ultraderechistas, sino que su permanencia no fue bien vista por una gran mayoría encabezada por Gonzalo Vallejo, recién designado director de la primera cadena.

Guerrero Zamora no tardó mucho en denunciar el sabotaje deliberado que se le hizo tanto a su persona como a su Celestina desde la dirección del ente público. Del tal manera, utilizó los espacios de algunos periódicos españoles para defenderse de los ataques que Vallejo había hecho en cuanto a la emisión, los costes y la calidad de su producción. En primera instancia, si bien este directivo programó la serie por obligación contractual a las 10:05 p.m., horario nocturno de más audiencia de TVE-1, el teleasta reveló que a esta no se le dio la adecuada promoción mediática porque le avisaron sin tanta antelación de que el primer capítulo se emitiría el 4 de octubre de 1983 y los restantes días 11 y 18 (citado en García Garzón 1983: 91). ${ }^{30}$ En segunda, el realizador respondería a Vallejo sobre

29.- Para Pérez Ornia resulta irónico que el informe del Ministerio de Hacienda sobre la ausencia de contabilidad patrimonial y transparencia en la gestión de TVE no se llegara a publicar ni tampoco que se hubiera amonestado al ente por sus actividades anómalas (1988: 387).

30.- Sospecho que en dicho contrato también se estipulaba la promoción del telefilm de $L C$ después de ser emitido, pues al igual que algunas de las series de TVE de los años ochenta, salió a la venta en formato digital en el mercado internacional. 
lo 'disparatado' que le parecía el costo de la serie, explicando que esto se debió a los incidentes de todo tipo que obstaculizaron el rodaje, así como a la mala gestión del jefe de producción y de otros profesionales de la televisión. ${ }^{31}$ Así pues, cuando asumió la segunda parte de la producción bajo el nuevo contrato, informa que contabilizó todos los gastos, los cuales llegaron a los 50 millones de pesetas por cuatro semanas de grabación (citado en Cañas 1983: s.p.).

A los pocos días de haberse publicado la réplica del teleasta hacia las declaraciones de Vallejo, Toni Soler, quien interpretó al personaje de la alcahueta en el telefilm, se uniría a la batalla contra las irregularidades de TVE. ${ }^{32}$ En este caso, aprovecharía el espacio que le brindó el diario $A B C$ para hacer pública la denuncia que había levantado en contra del ente por incumplimiento de contrato. La actriz aclara que en un principio pidió dos millones de pesetas como compensación por los nueve meses en que el rodaje se detuvo y en los que no pudo cumplir con otras obligaciones laborales en el ámbito del teatro al estar en plena disposición de la entidad pública. No obstante, la cifra de su demanda subió a quince millones porque su entonces representante, Eloy Herrera, vio la poca seriedad de cierto directivo para solucionar este asunto, ya que este le había ofrecido pagar únicamente un millón de pesetas y lo restante en 'especias'. Es decir, por medio de cuatro o cinco entrevistas que le harían a la actriz (citado en Amilibia 1983b: 91).

Otra de las razones que motivó a Soler a incrementar su indemnización fue que no volvió a ser requerida cuando se retomó la producción de la serie a mediados de 1982, teniendo en cuenta que a su personaje aún le faltaba por rodar dos secuencias largas. Indudablemente, esto le pesó a la artista, pero no tanto como el hecho de que alguien más la sustituyera como Celestina y además que no dijera ninguno de los diálogos que le quedaban pendientes. El representante de la actriz sugiere que fue TVE que permitió que se eliminaran o, en todo caso, se perdieran los once folios en los que la protagonista intervenía, a sabiendas de que por obligación contractual una de sus comisiones tenía que cerciorarse de que el telefilm de Guerrero Zamora, antes de programarse, estuviera en concordancia con el guion (91). A pesar de que no se tiene más información sobre cómo se solucionó el caso legal de Toni Soler, bien es cierto que este suceso, desde mi punto de vista, pone de relieve que la televisión bajo el primer año del gobierno del PSOE seguía funcionando corruptamente como en la etapa política anterior.

31.- La cifra comprende 800 figurantes, más de 30 actores y 60 técnicos (citado en Cañas 1983: s.p.).

32.- Como dato curioso, Guerrero Zamora había querido que Concha Rivera interpretara el papel de la alcahueta en el segundo intento de adaptar LC. Sin embargo, por cuestiones de agenda de la actriz no se pudo concretar su participación («Entrevista personal a Alejandra Torray»). 
En cuanto a la calidad de la producción, el teleasta descalificó en la prensa las voces de crítica que surgieron desde la propia TVE en contra de su serie de $L C$, sobre todo las provenientes de Gonzalo Vallejo y de una persona que se haría pasar por el académico español José Rubia Barcia. A saber, para Guerrero Zamora resultaba irónico que el director de la primera cadena arremetiera contra uno de los productos de casa bajo el argumento de que le parecía demasiado largo el telefilm seriado y que, principalmente, la edad de Nuria Torray, de entonces 49 años, era inadecuada para encarnar el papel de la doncella Melibea (citado en Cañas 1983: s.p.). Como respuesta a esta crítica, el realizador puntualizó que era insignificante juzgar la participación de la actriz solo por su edad sin siquiera valorar si con su registro dramático había hecho creíble al personaje. De cualquier forma, invitaba a este $\mathrm{u}$ otros de sus detractores a documentarse sobre la historia del teatro y los distintos ejemplos que ofrece de histriones maduros que han interpretado a personajes jóvenes (citado en García Garzón 1983: 91).33

A mi juicio, el argumento del realizador es acertado porque si se deja a un lado el factor de la edad, es fácil distinguir que Torray enriquece a Melibea con la fuerza interpretativa que había perfeccionado gracias a sus intervenciones anteriores en varios de los espacios dramáticos de TVE. Sin embargo, sospecho que el directivo tomó este aspecto como excusa para insinuar que la fórmula de Guerrero Zamora, de trabajar siempre al lado de su pareja sentimental, no tenía cabida en la televisión de la democracia. A saber, en su proyecto anterior Los mitos, el teleasta había puesto como condicionante en su contrato que la actriz protagonizara los trece episodios de la serie (Pérez Ornia 1988: 423). De tal manera, supongo que para que la crítica de Gonzalo Vallejo no se interpretara como una denuncia en contra de un posible caso de nepotismo, el director se vio obligado a aclarar que, desde un principio, el personaje de la hija de Pleberio había sido contemplado para una artista "con fuerza y con garra" en vez de que fuera para una persona adolescente e inexperta (citado en Cañas 1983: s.p.). Incluso, puntualizó que Nuria Torray se había negado a formar parte de la versión televisiva de $L C$, pero que después de tanta insistencia finalmente aceptó dicho papel (citado en García Garzón 1983: 91).

La segunda crítica a la que Guerrero Zamora respondió, apareció el 20 de octubre de 1983 en la sección 'Cartas al director' de El País bajo el título " 'La Celestina', en Televisión Española». En este documento, alguien bajo el nombre de José Rubia Barcia, entonces profesor de la UCLA, arremetió en contra de la producción bajo la premisa de la fidelidad textual. Es decir, para este impostor, quien durante su supuesta visita a España

33.- También me parece insignificante juzgar la interpretación de los actores José Caride (Sempronio), José Lara (Pármeno), Lola Santoyo (Lucrecia), William Layton (Pleberio) y Cándida Losada (Alisa) basándose únicamente en la edad real que tenían por aquel entonces. Estas críticas aparecen en el reporte de Snow (1983: 29) y en la reseña del impostor de José R. Barcia (1983). 
vio únicamente el primer capítulo, la serie traicionaba por completo el genio de Fernando de Rojas a causa de una evidente falta de documentación e incomprensión del verdadero significado del texto fuente. Del mismo modo, consideraba que haber alterado frases y escenas a conveniencia del realizador había contribuido a este problema, el cual calificaba de un verdadero 'crimen'. Como resultado de tales ausencias y modificaciones, el supuesto profesor creía que con la programación del telefilm se hacía notar el bajo nivel cultural y artístico del ente público, una acusación que, a mi parecer, en los medios impresos venía siendo constante desde los tiempos de la transición a la democracia.

El 25 de octubre, Juan Guerrero Zamora escribió en el mismo medio su réplica con un tono "tan zafio, brutal y de mal gusto» (Rodríguez Puértolas 1983: s.p.), poniendo en entredicho la identidad de la persona que firmó la misiva anterior. En mi opinión, la forma en que se expresa el teleasta es, de cierto modo, justificable porque en ese entonces estaba harto del sabotaje orquestado por ciertos profesionales de TVE hacia su Celestina, quienes sabían que era experto en la historia del teatro y, a su vez, que se había preparado para recrear este clásico. ${ }^{34}$ Sin embargo, estoy en desacuerdo en que tildara de 'profesorcillo', 'indígena ibérico' y 'cerebro fugado' a un académico que, como se supo el 17 de noviembre de ese mismo año, no tuvo nada que ver en el asunto y que ni siquiera había visitado el país desde 1981 (Rubia Barcuil 1983: s.p.). ${ }^{35}$ A pesar de que nunca se supo quién fue el autor de tal crítica, bien es cierto que el realizador y su esposa nunca más volvieron a participar en un medio que desde entonces les dio la espalda por cuestiones políticas ("Entrevista personal a Alejandra Torray»). ${ }^{36}$ Así, en 1987 publicaría, quizás a modo de despedida, el ensayo Teatro, televisión, cultura y otras manzanas (con o sin gusano) en la misma cesta, en el que critica principalmente la hipertrofia corporativista de TVE y el rechazo hacia las prácticas intelectuales dentro de su programación.

Desde mi punto de vista, una de las características que distingue a la serie de Juan Guerrero Zamora de las recreaciones anteriores basadas en LC, sobre todo la televisiva de Eduardo Fuller (1967) y la cinematográfica de César Ardavín (1969), es el abandono de una realización típicamente teatral en búsqueda del lenguaje fílmico y de la utilización, en su gran ma-

34.- Para la adaptación de este clásico español, el director se documentó con las ediciones primitivas y modernas depositadas en su biblioteca personal, así como con los primeros estudios celestinescos del siglo xx ("Réplica» 1983: s.p.).

35.- A Manuel Palacio se le hace irónico que El País, uno de los diarios de mayor repercusión cultural en España, no se disculpara por el error de no comprobar la identidad del impostor, siendo que tal misiva hablaba sobre "la 'fidelidad' de las fuentes» (2010: 19-20)

36.- No quisiera pensar que la polémica en torno a la serie de $L C$ fue una de las causas por las que la figura de Juan Guerrero Zamora no ha sido estudiada. Hasta la fecha no existe ningún compendio sobre su vida ni tampoco un análisis completo de sus obras televisivas. 
yoría, de exteriores o locaciones naturales. Sin embargo, este último rasgo que era común en la etapa cinematográfica de TVE a partir de los años setenta para aportar realismo y espectacularidad a las producciones dramáticas (Diego 2010: 33), no fue bien recibido cuando el hipertexto llegó a estrenarse en la pantalla chica. Específicamente, Haro Tecglen expresó su descontento hacia el protagonismo que la ambientación natural tiene en el telefilm como parte tanto del tratamiento libre como de la estética que el director siguió para alterar los eventos originales y crear escenas suplementarias. Como resultado de esta elección personal, el periodista cree que en la miniserie la trama de amor-pasión entre Calisto y Melibea tiene menor relevancia al grado de traicionar completamente la narrativa de Fernando de Rojas (1983: s.p.).

A mi parecer, el argumento del crítico es débil e incongruente por el hecho de que era sabido que Guerrero Zamora fue uno de los pioneros de la figura de autor en la televisión. ${ }^{37}$ De ahí que en los proyectos de recreación literaria que emprendía en el ente público siempre buscó plasmar su sello y lectura personal, es decir, apropiándose de las obras de partida. Sin duda alguna, tal aspecto no sería la excepción para adaptar este gran clásico de finales del siglo XV, ya que el teleasta anunció desde el inicio de la producción que esta Celestina sería mucho más suya que de Rojas (citado en "Guerrero Zamora» 1981: 93). Incluso, en esa misma fuente afirmó que una de las intenciones principales que tuvo para trabajar en el guion 'muy libre' del texto fuente fue la de reflejar por medio de su cámara el entorno social que se atisbaba en él. Por lo tanto, el enfoque de la fidelidad del que el periodista de El País se vale para analizar el telefilm resulta inadecuado porque no comprendió verdaderamente el tratamiento que el autor-realizador dio sobre todo a la ambientación. No obstante, sospecho que ello se debió a que fue víctima de este planteamiento que prevaleció por aquellos años en el ámbito de las reseñas de las adaptaciones de cine y televisión.

Contrario al punto de vista del crítico, encuentro interesante la libertad con que Guerrero Zamora describe visualmente, a partir de su interpretación como lector de la obra y conocedor del período histórico en que está circunscrita, tanto los rincones de la ciudad ficticia celestinesca como los eventos que ocurren en ella. Esto es porque interpreto dicho aspecto como el esfuerzo del director en dotar a su hipertexto no solo de dinamismo, sino también de un carácter español que de cierto modo termina aproximándolo al costumbrismo pictórico. A saber, las escenas que añade, lejos de ser un elemento ornamental para la trama del texto fuente, permiten al espectador conocer los modos de vida de los personajes en consonancia con la época del autor literario, particularmente la del grupo de los marginados. Esto si se tiene en cuenta que desde que se gestó el

37.- Diego y García de Castro consideran que Juan Guerrero Zamora fue el fundador de la figura de auteur en TVE (2010: 20; 2002: 27). 
proyecto en 1965, el realizador había planeado dar más protagonismo al mundo bajo que a la propia nobleza para poner de relieve la crisis que vivió la sociedad en la transición del Medioevo al Renacimiento español. ${ }^{38}$

El primer escenario que se observa en la miniserie es el laboratorio de Celestina ubicado en la planta baja de su casa. Mediante close-ups y travellings, el teleasta detalla los estantes llenos de ingredientes que la vieja utiliza para ejercer cinco de los seis oficios de los que es famosamente conocida, entre los que destaca el de maestra de hacer virgos. ${ }^{39}$ Con relación a este trabajo, el espectador presencia por primera vez en la historia de los espacios dramáticos de TVE una secuencia de un baño vaginal a base de un caldo caliente que sirve para curar el mal de madre que tiene Areúsa y así prepararla para la himenoplastia que la alcahueta le practicará. No dudo que esta escena breve haya sido impactante en el horario de máxima audiencia en que se estrenó el primer capítulo del telefilm, ya que se desarrolla sin ningún pudor y sin dejar nada a la imaginación, aunque eso sí los pechos de la prostituta permanecen cubiertos con su ropa. No obstante, en mi opinión, este momento, grotesco o no, es vital para que el televidente entienda que Celestina planea abolir el obstáculo que Pármeno supone con su fidelidad y leales consejos que da a su señor Calisto al entregarle a su muchacha con el himen reparado, así como prometerle una supuesta herencia que le dejó su padre Alberto hasta que se hiciera adulto. De tal manera, una vez formada la alianza de los tres (Celestina-Sempronio-Pármeno) sería fácil sacar provecho monetario del negocio de amor entre los jóvenes nobles.

En esta misma escena introductoria, la vieja recurre a otro de sus oficios para visualizar, a través de un espejo encantado, la historia que el criado de Calisto le cuenta sobre el momento en que su amo se encontró por primera vez a Melibea en su huerto lejos de la ciudad. Para recrear tal instante, el director se apoyó de música renacentista, casi de tipo místico, compuesta por Alejandro Massó, así como de una especie de flash-backs al inicio del relato y en una segunda toma cuando Sempronio se recompone tras haber olvidado algunos detalles. ${ }^{40}$ Esta acción queda interrumpida más adelante cuando el artefacto se le rompe a Celestina como si su poder mágico se hubiera agotado, lo cual ocasiona el espanto de una supersticiosa Areúsa. La reacción inmediata de Celestina resulta graciosa porque le pide a su protegida que, en vez de preocuparse por hechizar el espejo para evitar la mala suerte, mejor se enfoque en su baño de agua caliente

38.- Así lo explican el breve resumen argumental y otros documentos del expediente de censura del proyecto.

39.- Según Pármeno, Celestina era «labrandera, perfumera, maestra de fazer afeytes e de fazer virgos, alcahueta e vn poquito hechizera» (Rojas 1499: 71).

40.- Curiosamente, trece años más tarde, Gerardo Vera invitaría a Massó a componer la banda sonora de la segunda recreación cinematográfica de LC (1996). 
mientras ella sigue prestando atención a Sempronio, quien le cuenta más detalles de lo que sucedió después de que Calisto regresó a su casa.

Por medio de una lectura cercana de la secuencia anterior, es posible interpretar el papel que el director le dio a la temática de la hechicería en el inicio de su hipertexto. A mi juicio, Guerrero Zamora pudo haber tomado el espejo como referencia intertextual de la obra El encanto es la hermosura y el hechizo sin hechizo (1654) de Agustín de Salazar y Torres para vincular de cierto modo los actos hechiceriles de la alcahueta con el arte del engaño, pues no en balde intituló el acto I del telefilm Farsa y comedia de Calisto y Melibea. A saber, similar a lo que ocurre con la Celestina del autor literario mencionado, la del teleasta juega con este artefacto considerado tradicionalmente mágico para aumentar su credibilidad en el momento en que los presentes, en este caso Areúsa y Sempronio, creen tener una visión a través de este. Sin embargo, uno como espectador no cae del todo en este engaño porque es fácil darse cuenta de que la vieja finge tener poderes. Esto es precisamente a causa del estilo bufonesco con que actúa y la mayor importancia que le da a la historia del criado que a sus propios hechizos.

Al pertenecer este primer episodio al género de la farsa, considero que el director como especialista en teatro buscó ofrecer una perspectiva fantástica, pero también absurda de la realidad del mundo de la magia que aparece en la obra fuente. Esto se puede apreciar principalmente en una escena nocturna que sintetiza cinematográficamente el recuerdo que Celestina tiene sobre la madre de Pármeno, a quien la Inquisición culpó por ser bruja. ${ }^{41}$ En este flash-back, Claudina aparece en un campo junto a uno de sus pajecillos extrayendo muelas a un ahorcado para tenerlas como amuleto. A pesar de que este instante lleno de close-ups y planos generales podría resaltar las creencias supersticiosas sobre tales objetos que eran parte de los laboratorios de las hechiceras de la época para realizar conjuros de amor (Botta 1994: 57), el hecho de que la amiga-mentora de la vieja mantenga un perfecto equilibrio en la escala donde se alza para sacar con una sola mano las molares, resulta irrisorio para cualquiera. En mi opinión, esta respuesta en el espectador es parte de la función del género que el realizador desarrolla en esta primera parte de la miniserie $y$, precisamente, en esta escena porque la representó, según sus palabras, con "pura y truculenta ironía» (1983: s.p.).

Otro de los momentos en que Guerrero Zamora continúa con la farsa es el conocido conjuro que Celestina realiza a un hilado para provocar la supuesta claudicación de Melibea. En esta secuencia, el teleasta hace un buen trabajo describiendo visualmente cada paso del ritual con pri-

41.- Consúltese el trabajo de Cárdenas-Rotunno (2001) sobre la diferencia entre los términos 'hechicería' y 'brujería' según los tiempos del autor literario y, asimismo, sobre los motivos que llevaron a la Inquisición a ejecutar a Claudina. 
meros planos de los ingredientes, picados que muestran el círculo mágico donde se lleva a cabo y travellings de la alcahueta caminando por su laboratorio, todos ellos acompañados de música misteriosa y del reflejo de una calavera cuando termina la invocación a Plutón, el rey de los infiernos. No dudo que tales elementos hayan sido empleados tanto para intensificar el aura sobrenatural que envuelve al ambiente como para prestar cierta verosimilitud a este oficio de la vieja. Sin embargo, el que el director no se haya apoyado de efectos cinematográficos similares en la siguiente escena, en la que la alcahueta vende el hilado a la joven noble y a su madre en un palacete ambientado con decorados suntuosos medievales, es prueba eficiente de que no buscó dar importancia al posible efecto mágico del conjuro. ${ }^{42}$

A mi parecer, una de las funciones que Guerrero Zamora le da al objeto supuestamente hechizado es de servir como mero pretexto para que Celestina se acerque a Melibea y así comprarle la honra. Contrario a los críticos que defienden la eficacia de la magia en la obra, el realizador hace evidente en su telefilm que fueron causas naturales las que llevaron, por un lado, a Alisa a dejar a su hija a solas con la vieja. ${ }^{43}$ Es decir, si sale presto de la cocina de su casa para visitar a su hermana es porque se nota verdaderamente consternada por el mal de costado que le aqueja a esta, de ahí que también haya ignorado la advertencia que momentos antes le dio Pleberio sobre Celestina de no dejar a solas a su hija con Celestina. ${ }^{44}$ Y, por otro, a Melibea a seguir por su propia decisión el juego de esta mujer porque tiene pleno conocimiento de que se dedica a la medianería. No obstante, la joven se muestra reacia, al menos en apariencia, en momentos en que su honra se cuestiona, llegando a insultar a la vieja cuando exclama: "iquemada seas alcahueta falsa». ${ }^{45}$

Con el fin de que el negocio de amores no fracase, Celestina recurre a su verdadero poder, el de ser embaucadora. De tal modo, intenta convencer a la hija de Pleberio de que el verdadero motivo de su visita es obtener de ella la oración de Santa Apolonia que se sabe de memoria y, asimismo, su cordón que ha tocado muchas reliquias, esto como antídoto para el dolor de muela que Calisto padece y para que, una vez curado, pueda

42.- Incluso la voz en off del narrador que resume el primer episodio al inicio del acto II, cuestiona el efecto del hechizo: «iY Dios sabe si con el concurso del infernal Plutón, la alcahueta se salió con la suya!».

43.- Alan Deyermond considera que el conjuro afecta por igual a Melibea, a Calisto y a Celestina cuando intercambian tres objetos de valor simbólico: el hilado, el cordón y la cadena de oro. Véase su artículo de 1977.

44.- Como dato curioso, el personaje de Pleberio fue interpretado por el actor Luis Prendes en la primera parte de la producción, durante la polémica que rodeó a la miniserie. Y, en la segunda, William Layton asumió dicho rol ("Entrevisa personal a Alejandra Torray»).

45.- A diferencia de la Melibea telefílmica, la literaria hace plena referencia a la hechicería en su grito: "iquemada seas, alcahueta falsa, hechizera, enemiga de onestad, causadora de secretos yerros!» (180). 
alancear toros al siguiente día que es feriado. Después de escuchar dicha información, así como las cualidades del mozo de la boca de la trotaconventos, Melibea accede a entregarle su ceñidor, aunque le pide que vuelva mañana por la plegaria escrita. ${ }^{46} \mathrm{En}$ mi opinión, es evidente que la moza fílmica no está genuinamente preocupada por la salud de este hombre, que en la serie tiene veintiséis años, porque le habría dado enseguida la oración a la vieja. En cambio, me parece que su petición es una excusa porque de algún modo sabe que esta volverá con más noticias sobre él.

Poco después de que Celestina se marcha con el cordón, Melibea toma el hilado que esta trajo y se sienta frente al fogón de la cocina. En esta escena, la misma banda sonora del encuentro en el huerto vuelve a escucharse mientras que se observa a la joven en primeros planos oler el hilo y dirigir su mirada hacia las llamas. Inmediatamente, esta imagen se transpone con la del rostro de Calisto que está delante de la chimenea de su residencia medieval besando el ceñidor que la trotaconventos le acaba de dar. Desde mi punto de vista, el teleasta concede a ambos objetos una carga erótica que no tiene conexión directa con el efecto mágico o diabólico del conjuro. A saber, la hija de Alisa empieza a adorar el hilado de la alcahueta porque sabe que gracias a la intercesión de esta podrá ver al hombre por el que empieza a sentir algo. Por su parte, Calisto goza del cordón en el sentido en que pronto podrá hacer lo mismo con los labios de Melibea o, en su defecto, su cuerpo. Es más, se queda con este objeto para poder llevarlo más tarde a la iglesia para agradecer este primer triunfo. Dicho acto me parece que está en consonancia con la parodia de la imaginería religiosa que el estudioso López-Ríos ve inserta en la sátira del clero de la obra (2012: 203).

Como innovación a la trama celestinesca, la secuencia que abre el acto II titulado Tragicomedia de Calisto y Melibea ocurre en una plaza de toros de la localidad de Arcos de San Juan en Soria. En este lugar, el realizador grabó con planos generales, close-ups y travellings al joven noble practicando esta actividad a caballo frente a varios espectadores que incluyen a la familia de Pleberio, a Celestina y a sus protegidas, así como a cientos de extras que hacen de los habitantes de la ciudad. En términos monetarios, el rodaje de tal escena representó un despilfarro del presupuesto inicial a causa de la mala gestión de la productora de TVE. El director comenta que tardó cuatro días en grabarla porque no se consiguió a tiempo el equipo básico para practicar este arte taurino (el toro, el torero y la lanza), lo cual implicó un gran despliegue tanto técnico como personal que llegó a sumar las ochocientas personas (citado en Amilibia 1983a: 83).

Mientras tanto, en términos narrativos, resulta relevante entender la finalidad que dicha escena tiene en la trama de la miniserie, más allá de

46.- Entre estas cualidades se encuentran el ser 'franco', 'alegre', 'noble de sangre' y 'ángel caído del cielo'. 
calificarla de ser 'infiel' al 'original' e, incluso, de 'absurda'. ${ }^{47}$ En primer lugar, la intención que Guerrero Zamora tuvo con esta fue la de ilustrar una corrida de toros renacentista como en los tiempos de Fernando de Rojas ("Entrevista personal a Alejandra Torray»). A partir de ello, considero que el realizador logra explicar atinadamente la función de este espectáculo perteneciente al ocio urbano de finales del Medioevo durante las celebraciones festivas, es decir, como "alivio de tensiones cotidianas y cierta cohesión social» (Rodrigo-Estevan 2007: 79). De ahí que el telespectador observe reunidos a diferentes gremios de la ciudad en el mismo espacio para disfrutar de las destrezas caballerescas de Calisto, aunque eso sí pudiendo distinguir el prestigio y el poder que tenía la aristocracia. Esto se debe a que el teleasta ubicó a los nobles en los balcones principales, mientras que a la gente común, como a las prostitutas de la alcahueta, en otros lugares separados de ellos.

En segundo lugar, según el resumen argumental del proyecto fílmico, el director tuvo la intención de convertir tal escena en el momento clave que evidencia cómo la voluntad de Melibea queda presa. ${ }^{48}$ Es decir, en el que finalmente se enamora del hombre que la pretende. Esto se puede corroborar cuando la doncella aparece en primeros planos observando con detenimiento a Calisto, quien hace gala del manejo de su caballo en los quites con el toro. Pese a que un instante el joven noble corre el riesgo de ser derribado, ocasionando el sobresalto de los espectadores, al final logra obtener la admiración popular. ${ }^{49}$ Tal efecto produce celos en Elicia, la protegida de Celestina, pues cuestiona con enfado la atracción que este hombre valiente siente por la hija de Alisa. Al menos así se interpreta cuando dice: "¿Qué le ve a Melibea?».

Una vez que concluye el evento, Guerrero Zamora añade otra escena a la trama en que se ve a la familia de Pleberio ser llevada en carruajes de regreso a su palacio a excepción de Lucrecia. Esta, en cambio, se ha quedado en la ciudad para alcanzar a Celestina entre la multitud de gente y darle el recado de su ama de que le devuelva el cordón y, de paso, que la visite porque se encuentra fatigada de dolor de corazón. Aunque la vieja no se va con ella inmediatamente porque tiene que atender otros asuntos en la taberna de la ciudad, el director da a entender que más tarde se dirigirá a la casa de la joven con su ceñidor. Sin embargo, una vez ahí, Celestina se ve imposibilitada a entrar en la alcoba de esta por miedo a que Pleberio la descubra. Como consecuencia, la criada se convierte en

47.- La académica Iglesias emplea dicha terminología en su reseña de la recreación de Guerrero Zamora (2017: 392).

48.- Consúltese el breve resumen argumental en la misiva que José Luis González Álvarez envía al Ministerio de Información el día 19 de agosto de 1964 (Expte no. 108-65, caja 36.0404).

49.- De acuerdo con Díaz Marcilla, los nobles que participaban en este tipo de eventos normalmente eran de segunda o, incluso, de tercera línea (2016: 219). 
vocera de la trotaconventos, que en ese instante está escondida en las tapias del huerto, para dar a la doncella el remedio a su padecimiento. Si bien desconozco si esta fue una de las escenas que la actriz Toni Soler no pudo grabar en la segunda parte de la producción iniciada en 1982, el hecho de que la actriz Mercedes Barranco recite los diálogos en su lugar me parece interesante.

A mi juicio, el teleasta tomó como referencia intertextual la Segunda Celestina (1534) de Feliciano de Silva para demostrar que en la mediación de amores, la intervención de los criados es más importante que la de la propia Celestina, cuya función está limitada a acordar citas. A saber, tal como ocurre en esta continuación de la obra rojana cuando los sirvientes posibilitan el encuentro de los jóvenes nobles Polandria y Felides, la Lucrecia telefílmica actúa como la auténtica medianera o tercera a partir de la escena anterior, pues muestra tener pleno conocimiento de lo que padece su ama. Sin embargo, para seguir con las reglas de este oficio, finge no saber si el dolor que siente su ama es nuevo o si procede de un mal pensamiento. Melibea, quien no está del todo segura si las preguntas que acaba de escuchar provienen de la cosecha de su sirvienta o de la misma Celestina, le exige que diga el nombre del mal que recién obtuvo. Lucrecia, vanagloriándose de su sabiduría, contesta que no necesita de celestinas para explicarle lo que el 'amor dulce' significa.

Después de escuchar la explicación de su criada experta en amores, Melibea le ruega que no tarde más en darle el remedio a su mal, que tanto ella como la madre Celestina saben. Cuando Lucrecia pronuncia el nombre de Calisto como la cura de su enfermedad de amor, esta se desmaya instantáneamente. Posteriormente, se repone y confiesa que desde que el caballero le habló de amor en su huerto, "sus palabras [le] fueron enojosas como alegres luego». Una vez confesada la pasión que siente por él, la sirvienta, como representante de la alcahueta, busca hacer posible que Melibea no solo vea, sino converse con Calisto esa misma noche a las doce en el huerto, sin importarle del todo la honra de su ama. No obstante, la joven noble negocia con ella para que mejor se encuentren al día siguiente y a la misma hora por entre las maderas de las puertas. De tal manera, ella quedaría salvaguardada en caso de que algo saliera mal.

Mientras el primer encuentro entre Calisto y Melibea queda concertado en esta escena, Guerrero Zamora añade a la trama celestinesca nuevas secuencias que retratan con bastante realismo el mundo del hampa, las cuales habían sido motivo de censura según los archivos del proyecto fílmico en 1965. En mi opinión, al igual que Feliciano de Silva, el realizador buscó ofrecer más detalles sobre los temas de la prostitución y la rufianería tratados en la obra de Rojas, esto tomando en cuenta la realidad histórica de finales del Medioevo. Desde el inicio de la miniserie, el espectador observa que Celestina tiene a dos pupilas ejerciendo este oficio de manera clandestina bajo el techo de su casa. Por un lado, Elicia se dedica 
a atender en la segunda planta a Crito y a otros estudiantes universitarios que como él visitan la ciudad. Y, por otro, Areúsa en el palomar o ático mantiene citas con hombres a los que la alcahueta usa para sus embustes, entre ellos Pármeno.

A mi juicio, una de las intenciones principales que el realizador tuvo para desarrollar esta temática fue la diferenciar a las dos muchachas de las otras rameras de la taberna, puesto que se observa en varios momentos que estas gozan de más libertades y mejores condiciones de vida. Uno de estos es la escena en que ambas utilizan, aunque de forma grotesca, las cremas, los perfumes, el maquillaje u otros menjurjes del laboratorio de la vieja para tener una buena apariencia personal ante sus clientes. Otro se da en el acto II cuando las dos están al lado de Celestina en las gradas de la plaza de toros, portando ropas coloridas y actuando con cierta petulancia como si fueran parte de la nobleza. Pese a que este comportamiento se podría considerar incongruente con las precauciones que se cree que la alcahueta toma en la obra fuente para no ser denunciada, dada la clandestinidad de su oficio (Iglesias 2011: 202), considero que en el telefilm tiene una función más bien irónica. A saber, el teleasta tomó el día feriado en que se celebra la corrida para insertar el conflicto social que subyace en el hipotexto. De ahí que se observe al grupo de los marginados tener una total libertad de hacer lo que le plazca, al menos por un día. ${ }^{50}$

Un tercer momento ocurre cuando Celestina y sus protegidas salen de la plaza rumbo a la taberna. En esta escena grabada en exteriores que muestra tanto a los pobladores como a mercaderes de la urbe en constante movimiento, la trotaconventos se topa con unos religiosos y, posteriormente, con Lucrecia. Dichos encuentros le hacen recordar la mejor época de su oficio en la que no le faltaron muchachas ni comodidades debido a la clientela de todo tipo que tenía, incluidos ciertos miembros del clero a los que Elicia tacha de no ser ningunos santos.

A este respecto, la vieja trae a colación una anécdota muy similar a la de la cena XXIX de la Segunda Celestina, para dar cuenta del estilo de vida liberal y los vicios de los trinitarios en oposición a los ideales reformadores de la Iglesia castellana de aquellos tiempos (Ladero Quesada 1990: 11213). En dicha historia de tintes satíricos, un fraile gordo que frecuentaba años atrás el prostíbulo clandestino de la alcahueta, se esconde en una tina llena de agua para no ser descubierto por el rufián-amante de una de las mozas. Celestina cuenta con risas que cuando el líquido se derramó a causa de la gran barriga del trinitario, esta y su muchacha fingieron ante el criminal que el agua que veía en el piso era la orina de ellas, salvando así el pellejo del religioso.

50.- Esto lo confirma Sempronio en la miniserie cuando platica con su amo Calisto: «es feriado y la ronda no se prima. La justicia da hoy más libertades». 
Un último momento es la secuencia en la taberna donde está reunido el submundo de la ciudad celestinesca, la cual la incomodó a la censura franquista por el realismo en que se representaba en el guion del proyecto «toda su corte milagrera y sórdida, tabernaria y pícara». ${ }^{51}$ En la escena telefílmica, el rufián Tripa en brazo, Quincia y otra de sus prostitutas a su cargo, exigen a la alcahueta que les cuente el negocio que trama con Lucrecia, ya que la vieron conversar con ella en la calle. ${ }^{52}$ Tras ser insultada por estas rameras envidiosas, Celestina las distrae respondiendo cómicamente que la criada de Melibea la buscó para pedir que le escribiera su registro de doncella (de la vieja), el cual, según añade Areúsa, estaba en el sitio que ella misma dejó vacante. La respuesta de la moza provoca que Traso, otro de los rufianes presentes en el lugar, se burle de su compinche Centurio porque da a entender que esta tiene encuentros con varios hombres sin su conocimiento. Inmediatamente, este último rufián muestra un comportamiento que, de acuerdo con Gimber, era común en estas figuras cómicas estereotipadas de la literatura española (1992: 67), pues contesta fanfarroneando y amenazando a su adversario. Sin embargo, al no llevar consigo una espada, ya que la empeñó hace unos días, Centurio queda en ridículo ante todos.

Más tarde, en ese mismo ambiente tabernario-picaresco, Quincia, movida por los celos que tiene hacia la prosperidad de la casa de citas de Celestina, insulta a Elicia y a Areúsa al compararlas directamente con Lucrecia. Esto causa el enojo inmediato de ambas y, en defensa, vociferan que ellas viven mucho mejor de su oficio que las criadas de las nobles. A su parecer, ello se debe a que estas últimas reciben vejaciones, abusos físicos y limitaciones económicas por parte de sus amos, ya que, por ejemplo, las obligan a pagar las sayas rotas con las que las visten con diez años de trabajo o, incluso, se olvidan de sus nombres. En vista de tales maltratos hacia el servicio doméstico femenino, la Areúsa telefílmica, muy en línea con su coetánea literaria, lleva más allá la crítica social hacia la nobleza, puesto que insinúa con ironía ver en los pajes la virtud elevada que los nobles de nacimiento carecen. ${ }^{53} \mathrm{Tal}$ comentario provoca la celebración de algunos de los presentes.

Otra escena nueva en la serie en la que Guerrero Zamora manifiesta el conflicto social latente en la obra de Rojas tiene lugar en la taberna, justo

51.- Cita tomada de la carta que José Luis González Álvarez envía al Director General de Cinematografía y Teatro el día 17 de mayo de 1966 (Expte no. 108-66, caja 36.0404).

52.- Tripa en brazo y Quincia son personajes exclusivos de la Segunda Celestina. En esta obra, el primero es compinche de Traso el Cojo, mientras que la segunda es criada de la madre de Paltrana y amante del rufián Pandulfo.

53.- Según Ladero Quesada, en la Castilla del siglo xv, este tipo de comentarios estaban destinados a minar los fundamentos aristocráticos del orden social, pues personajes como Areúsa rechazan que sean las obras que determinen el poder del individuo y no la herencia (1990: 111). 
después de que Celestina saliera a ver a Melibea. En este espacio, Crito y Areúsa, empoderados por la ausencia de la alcahueta, organizan una Danza de la Muerte inspirada en el códice de El Escorial. Su propósito es claro: llevar este espectáculo hacia la casa de Calisto, a quien consideran el hombre más medrado de la ciudad, y así hacer efectiva la libertad que la justicia les concede en el día festivo. Es decir, la oportunidad de poder invertir las jerarquías y caricaturizar al clero y a la aristocracia sin sanción alguna. Para ilustrar dicha subversión, el realizador empleó música medieval carnavalesca acompañada de imágenes en que se aprecian a varios estudiantes portando máscaras de calaveras, a Centurio con una corona de rey en la cabeza y a Elicia llevando tanto una mitra como una casulla papal. ${ }^{54}$

Una vez que todos los convocados a la siniestra farsa llegan las afueras de la casa del noble, alegres y alcoholizados, la moza de Centurio, secundada por otro estudiante que supongo es uno de sus amantes, sacan a la luz el negocio de amor entre el amo de Pármeno y la hija de Alisa. Al respecto, la prostituta insinúa ante los presentes que ella fue la que facilitó el contacto con la doncella por lo que le agradece irónicamente a Calisto el haberle dado esa oportunidad. A continuación, Areúsa y el estudiante proceden a imitar a Melibea y a Celestina, respectivamente, para seguir mofándose del joven, ya que sugieren que con engaños este no se dará cuenta de que su amada no es del todo gentil. Tales burlas provocan la furia de Calisto quien decide salir a defender su honra con espada en mano. Cuando este se encuentra afuera de su casa ve a la verdadera vieja siendo alabada por todos como «la reina de la alcahuetería y del amor carnal», aunque en realidad esta acababa de llegar de las tapias del palacio de Pleberio, siendo obligada por los estudiantes a participar en el tumulto.

Las secuencias nocturnas anteriores son un ejemplo del esfuerzo del teleasta en hacer explícita «[la] antigua, inconfesada ansia vindicante [del mundo de los marginados] contra la clase señora», misma que se refleja en el hipotexto a través tanto del comportamiento como de los diálogos de los criados y las prostitutas. ${ }^{55}$ El hecho de que el director decidiera trasladar esta crítica social de Rojas a las circunstancias del país, primero en un intento fallido durante la dictadura y, en el definitivo, en la transición, tuvo un claro propósito satírico. A mi juicio, Guerrero Zamora, sirviéndose de la misma fórmula que aplicó al escribir el guion de la recreación cinematográfica Fuenteovejuna (1970), buscó hacer en la miniserie de LC una perfecta alegoría del declive de los pilares del Régimen, es decir, de su totalitarismo, su caciquismo, así como de los valores de la Iglesia católica,

54.- La misiva de José Luis González Álvarez y el resumen que da el narrador en voz en off al inicio del acto III describen la intención de esta farsa macabra.

55.- Cita tomada del breve resumen argumental (Expte no. 108-65, caja 36.0404). 
a partir de la decadencia de las estructuras de la todavía sociedad feudal que Fernando de Rojas da cuenta en su obra. ${ }^{56}$ De ahí que se observe al pueblo celestinesco rebelarse con antorchas para combatir los excesos de la nobleza y del clero durante la bufa danza macabra, cuyo efecto igualitario ocurriría, tentativamente, con las muertes de Celestina, de los criados de Calisto y de los propios amantes nobles.

Mientras que los organismos censores a cargo del entonces Ministerio de Información interpretaron las escenas mencionadas como 'revoltosas', pues propusieron eliminarlas de tajo en el guion del largometraje, cuando estas se lograron representar enteramente en el estreno de la miniserie en TVE-1, curiosamente los críticos no captaron del todo el objetivo del director. Considero que ello se debió, por una parte, a que estos prefirieron valerse del escándalo en relación a los costos de la producción, pero, sobre todo, de la supuesta infidelidad a la obra para despreciarla por «el feísmo, el asco, la crueldad y el sadismo» con que, según Haro Tecglen, el realizador retrata varios momentos (1983: s.p.) Y, por otra, a que cuando el telefilm se trasmitió en la recién instaurada etapa democrática, los intereses tanto políticos como temáticos dentro de la programación de TVE comenzaron a cambiar. A saber, los directivos del ente público pretendieron conectar más con los televidentes a través de la producción de series que reflejaran los problemas que vivía la sociedad de ese entonces, en vez de recurrir a conflictos remotos y a los ya saturados autores de obras clásicas (García Castro 2002: 75; Guarinos 2010: 106).

Como parte de los géneros de la comedia y la tragedia que se desarrollan en el acto II del hipertexto de 1983, el realizador se encargó de representar sombríamente los modos de vida de la época del autor literario a través de la clase marginal. Si bien es por ello que esta tiene un mayor protagonismo que el mundo de los señores, en mi opinión, eso no significa que la historia de amor-pasión entre Calisto y Melibea sea un mero pretexto para la trama. Por el contrario, esta se convierte en el motor que lleva a organizar la Danza de la Muerte, sobre todo porque el director buscó insertar en ella la intención moral que como lector interpretó en el texto de partida. Esta es la de revelar en aquel ambiente rufianesco "cómo el sentimiento amoroso que degenera en lujuria lleva siempre la muerte aparejada». ${ }^{57}$ Es por esto que Areúsa y el estudiante se mofan de los jóvenes nobles porque saben que tarde o temprano darán rienda suelta a un apetito sexual mundano, aunque lo traten de encubrir o soslayar.

Este enfrentamiento ideológico entre las reglas sociales que exigen defender la honra públicamente y las aspiraciones personales, se comprueba

56.- El tratamiento 'subversivo' que Guerrero Zamora dio para recrear la tragedia de Lope de Vega ocasionó la supresión de cuarenta y siete de sus fragmentos por ser considerados inadecuados a los intereses históricos-políticos del tardofranquismo (Wheeler 2012: 158-9).

57.- Cita tomada de la misiva que José Luis González Álvarez envía al Director General de Cinematografía y Teatro el día 17 de mayo de 1966 (Expte no. 108-66, caja 36.0404). 
en el momento en que Calisto sale de su casa a espantar a los marginados que lo han denostado apuntándoles con su espada e, incluso, a la propia Celestina a la que acusa de ser traidora. Para tranquilizar al mozo, la vieja se insulta a sí misma, llamándose 'tonta' y, posteriormente le menciona al caballero que Melibea lo ama y desea ver. Sin dilación alguna, el comportamiento bravío de este se desvanece y, desesperado, le ofrece una cadena de oro a la alcahueta a cambio de que le diga el resto del mensaje que trajo de parte de su señora. Una vez que esta le comunica que concertó una cita entre ellos a las doce de mañana noche en el huerto, el joven rompe su espada en un acto desesperado. Si bien este suceso puede resultar inverosímil al espectador, representa, desde mi perspectiva, el momento en que el personaje finalmente se ha sometido, sin importarle su honra, a un amor-pasión que traerá fatales consecuencias.

Otra escena que el teleasta añade a la trama para seguir ilustrando el mencionado conflicto ideológico ocurre en la cámara de Melibea, minutos antes de que se encuentre con Calisto. En este lugar rodeado de decorados elegantes e iluminado con velas, Lucrecia le cuenta a su ama que el pueblo, a sabiendas de que el joven la corteja, ha empezado a murmurar que el linaje de este representa un gran obstáculo para su felicidad. Es decir, según las habladurías, Pleberio, al ser tan riguroso por la cuestión de pureza de la sangre, no permitiría que su única hija se casara con uno de los descendientes de judíos conversos que hace más de cincuenta años el concejo de Toledo había desamparado. En vista de que el patriarca no preverá sus bodas por estar obsesionado con 'sucesos tan rancios', la criada, quien parece dominar la voluntad de Melibea, le aconseja con comicidad que 'Doña Naturaleza' será quien lo haga. ${ }^{58} \mathrm{Al}$ escuchar tal respuesta, la joven niega rotundamente que el deseo carnal impere sobre su razón. Sin embargo, las ansias que tiene de que den las doce de la noche para ver a su amado, indican todo lo contrario.

A mi parecer, la escena anterior tiene de cierto modo una mayor conexión intertextual con la Segunda Celestina que con la propia obra de partida, específicamente, por el parecido que hay entre el comportamiento de Polandria y el de la Melibea telefílmica. A saber, ambas son doncellas que no piensan por sí mismas ni actúan con la misma conciencia autónoma que su coetánea rojana tiene desarrollada. Debido a ello, estos dos personajes necesitan del sabio consejo de sus criadas para superar la encrucijada de que sus progenitores no les permiten elegir marido. Así pues, Poncia y Lucrecia proponen a sus respectivas señoras una vía alternativa al matrimonio por imposición para poder ser felices al lado de sus caballeros. La primera le recomienda a Polandria que, antes de perder la

58.- Este conflicto religioso-social recoge, de acuerdo con Orozco Díaz, «la realidad espiritual de la España de entonces [...], el ambiente de diferencias, odios e incompatibilidades de esa compleja sociedad de conversos y cristianos viejos» (1957: 10). 
virginidad, se case clandestinamente con Felides, el hombre a quien ama. Antes bien, la joven la desobedece $y$, para defender su honra, la criada termina convenciéndola de que organice en cuanto antes su desposorio público. Mientras tanto, la sirvienta en la miniserie le insinúa a Melibea que se una físicamente a Calisto con el fin de disfrutar libremente de un amor que Pleberio habría impedido.

Sin lugar a dudas, los consejos anteriores son un ejemplo de las diferentes ideologías que tanto Feliciano de Silva como Guerrero Zamora buscaron introducir en sus textos. El consejo de Poncia, al ser portavoz del discurso moral del escritor del siglo XvI, defiende los cánones institucionales arraigados al epistema medieval sobre el matrimonio, la honra y el cristianismo, como los fines últimos de la existencia (Rodríguez Cascante 2001: 38-9). En contraste, el de la Lucrecia del texto televisual va encaminado a trasgredir esas convenciones, quizás conservadoras y represivas, de una estructura sociopolítica en decadencia. A mi parecer, el director trató de llevar esta crítica, que en la obra de Rojas se refleja sobre todo en la forma en que Melibea ejerce su libertad individual, a la época de la transición hacia la democracia. Esto es para evidenciar el reemplazo de valores del franquismo por aquellos promovidos por la Constitución española en 1978 (la libertad, la justicia, la igualdad y el pluralismo político). Sin embargo, las escenas posteriores contradicen este propósito a causa de lo que creo que es en parte una interferencia intertextual con la obra continuadora de la tradición celestinesca.

Cuando Calisto llega a las afueras de la casa de Pleberio para encontrarse con su amada, esta le pide a Lucrecia que se vaya a acostar un rato. Inmediatamente la criada se retira del huerto, no sin antes musitar con cierto sarcasmo que en el 'valle de lágrimas' en que viven habrá una doncella menos. Desde mi punto de vista, este comentario resulta contradictorio con el espíritu trasgresor que se había observado en ella momentos antes, ya que ahora parece recriminar con un tono moral, similar al de Poncia en la Segunda Celestina, el hecho de que su ama vaya a perder la virginidad. Mientras tanto, Melibea sigue con su batalla ideológica en la cita nocturna que tiene con el joven, pues, por una parte, evita a toda costa que este dañe su honra cuando salta desesperado las tapias para estar junto a ella. Y, por otra, le ruega a su señor que contenga su deseo (sexual) hasta la siguiente noche en que se vuelvan a encontrar o, en otras palabras, en que consumirán ese sentimiento mundano.

El momento anterior es clave en la trama del hipertexto porque la actitud de ambos enamorados, sobre todo la de Calisto, deja ver en todo su esplendor la lujuria que el uno inspira en el otro. A partir de ello, la intención catártica, por lo tanto moral, que Guerrero Zamora interpretó en la obra de partida surtiría efecto con la muerte de los personajes que participaron en el negocio de amor de la pareja noble, comenzando con la 
de la alcahueta. ${ }^{59}$ En contraste con el hipotexto, en la miniserie, Sempronio y Pármeno dan por sentado que el primer encuentro entre su amo y Melibea irá para largo, por lo que aprovechan ese tiempo para ir a donde Celestina a cobrarle parte de las ganancias que les corresponden del dichoso negocio. Sin embargo, esta decisión apresurada tiene que ver con el estado en que se encuentran los criados, pues han estado bebiendo el vino que hurtaron de la alacena de Calisto. A mi parecer, el director buscó resaltar a través de tal comportamiento lo ruines que estos hombres llegan a ser a lo largo del telefilm. Es decir, con el robo a su amo no solo muestran el odio que tienen hacia el vasallaje de la clase señora, sino lo cobarde que son porque necesitan del alcohol para armarse de valor e ir a cumplir con su objetivo.

Una vez que llegan a la casa de Celestina, esta se muestra indispuesta a repartir tanto el dinero como la 'cadenilla' de oro que ahora da por perdida, bajo el argumento de que lo que ellos pensaron como promesa era en realidad una expresión de cortesía que no tenían que tomar tan literalmente. Por lo tanto, según ella, las ganancias que obtuvo de manos de Calisto fue por méritos propios. Tales palabras causan la ira inmediata de Sempronio y Pármeno, quienes optan por no prestar más atención a las excusas de la vieja avarienta. Así, con espadas en mano amenazan con matarla si no les da lo que les corresponde. Pese a que ella les advierte que si se atreven a hacerlo, el asunto de su amo y de ellos correrá por las plazas, los criados comienzan a destruir sin piedad el laboratorio en búsqueda de la cadena de oro.

En otro trabajo señalé que Guerrero Zamora modificó las circunstancias del asesinato de la Celestina literaria, convirtiéndolo en la más cruel de las muertes de las recreaciones de cine y televisión de LC (Villalobos Graillet 2016: 394). En mi opinión, el realizador siguió una perspectiva histórica para dotar de realismo a una escena que bien pudo haber acontecido en el mundo urbano del Medioevo. A saber, similar al comportamiento de los agresores u homicidas de aquella época, los criados telefílmicos actúan impulsivamente a causa del efecto del alcohol y del acaloramiento progresivo de los ánimos en la discusión con la trotaconventos. De tal modo, estos proceden a hacerle daño a las dos mujeres que se encuentran en el interior del hogar, uno de los espacios comunes en la geografía del crimen medieval (Córdoba de la Llave 2004: 401). Por su parte, Pármeno golpea a Elicia para evitar que siga llamando a los vecinos a que acudan a socorrer a la madre, mientras que Sempronio le arroja a esta lejía y otros químicos que encuentra en el laboratorio.

Momentos más tarde, Celestina aparece en un plano picado embarrada de sus propios menjurjes pidiendo la clemencia de su agresor. Este, moti-

59.- Esto lo explica José Luis González en la carta que envía al Director General de Cinematografía y Teatro el día 17 de mayo de 1966 (op.cit.). 
vado por su compinche, le estrella un jarrón en la cabeza, lo cual causa su muerte instantánea.$^{60}$ Acto seguido, Sempronio encuentra la cadena que todo ese tiempo estuvo debajo del manto de su víctima, sin embargo, su alegría no dura mucho porque se da cuenta del crimen que acaba de cometer. Así pues, él y Pármeno empiezan a huir asustados de la escena porque tanto los vecinos como los alguaciles llegarán en cualquier momento. Cuando eso sucede, los sirvientes deciden arrojarse por la ventana del palomar al barranco para evitar ser decapitados por la Justicia. ${ }^{61}$

Este segundo episodio de la miniserie concluye con la escena en que Elicia regresa sola al laboratorio a llorarle al cuerpo inerte de Celestina. Para ilustrar este momento de luto, pero sobre todo para intensificarlo, el teleasta añade música dramática, primeros planos de la cara demacrada de la prostituta y maldiciones que esta vocifera hacia su amante y el otro asesino de su maestra. No dudo que este instante, así como el del homicidio de la alcahueta o el del acto suicida de ambos criados de Calisto hayan sido perturbadores para la audiencia nocturna de TVE-1 por el realismo psicológico con que se representan. No obstante, desde la contemporaneidad, este elemento me parece plausible en el hipertexto por dos razones.

La primera se debe a que este permite al espectador adentrarse en los estados de ánimo y los conflictos psicológicos de los personajes que aparecen en dichas escenas, en especial el de Pármeno. Al respecto, en el telefilm se muestra a este individuo como el manipulador de la voluntad de Sempronio, comportamiento muy parecido con el caso de Lucrecia y Melibea, pues lo induce a matar a la mujer por la que ha sentido odio desde pequeño. Así, su muerte significa para él el haberse vengado finalmente de la codicia y de las falsas promesas de la alcahueta. La segunda razón obedece a la intención del teleasta de recrear la obra de Rojas alejada de las convencionalidades estéticas e interpretativas de las adaptaciones de los textos clásicos que se estrenaron por aquellos años. De tal manera, en esta escena del hipertexto se despoja de la teatralidad al llevar la acción por una vía más natural, aunque, sin llegar a ser la realista cinematográfica. Sin embargo, el director no daría continuidad a este tratamiento en el último episodio de la miniserie, pues tanto el lenguaje como la interpretación de la pareja protagónica son más bien teatrales. ${ }^{62}$

60.- Este tipo de homicidio era frecuente en la Europa medieval, pues, según Crouzet-Pavan, había agresores que cogían cualquier objeto a su alcance, que no necesariamente eran catalogados armas, para dañar a sus víctimas (1984: 917 y 923).

61.- A diferencia de la obra fuente, la decapitación es el castigo que el Sempronio telefílmico cree que él y Pármeno recibirían de ser prendidos por los alguaciles.

62.- En la miniserie Los mitos, Juan Guerrero Zamora había intentado también interrelacionar el lenguaje teatral con el televisivo, tratamiento que, según Manuel Palacio, resultó frío y ocasionó el distanciamiento de los telespectadores (2012: 312). 
Desde el título del auto III, Tragedia de Calisto y Melibea, uno como espectador puede inferir que a los protagonistas les espera un destino fatal como consecuencia de una serie de eventos. El primero que ofrece Guerrero Zamora es el ajusticiamiento inmediato de Sempronio y Pármeno, quienes irónicamente sobrevivieron, aunque en condiciones bastante deplorables, a la caída al barranco o, en todo caso, a su intento de suicidio. ${ }^{63}$ Cuando Calisto se entera por boca de Sosia de que ambos criados fueron decapitados esa misma mañana en la plaza por haber asesinado a Celestina, este, conmocionado, promete vengar su injusto procesamiento y, al poco rato, sube a su alcoba a descansar. ${ }^{64}$ En seguida, el director contrapone este momento dramático con otra escena en la que se muestra con un travelling a Melibea subir a lo alto de su torre. Desde ahí, ella dirige su mirada hacia el palacete de su amado como una forma de consolarlo a distancia por la muerte de sus sirvientes, pero también, aunque irónicamente, como un recordatorio de que esa misma noche se verán para consumir su amor.

El segundo evento es el mencionado encuentro nocturno de esta pareja en el huerto. Antes de que esto suceda, Melibea, afligida, cree que las causas de la tardanza de Calisto se debe a alguno de los siguientes escenarios: el que la Justicia haya sentenciado a su amado cuando salió a defender la memoria de sus criados muertos; el que la ronda lo haya acometido en el camino hacia la casa de Pleberio sin saber de quién se trataba; o bien el que el pueblo lo haya perseguido para vengarse del triste fin que tuvo Celestina. ${ }^{65}$ En cualquier caso, el espectador sabe que todo ello, así como las características ennoblecedoras que le atribuye son falsas. Esto es precisamente porque el joven no ha salido a defender su honra tras los eventos trágicos que ya son noticia divulgada en la ciudad ni mucho menos se ha comportado con su señora como un buen amante cortés.

$\mathrm{Al}$ respecto, considero que el teleasta dota de cierta parodia a este personaje según la interpretación que hizo de él en la obra fuente porque lo caracteriza como un hombre carente de paciencia desde la primera cita que tiene con la doncella e, incluso, en la segunda cuando intenta saltar las tapias sin escala alguna. Sin embargo, este comportamiento atolon-

63.- Sempronio aparece en la escena de su ajusticiamiento con la cara magullada y con el brazo quebrado, mientras que Pármeno se muestra inconsciente.

64.- Según Iglesias, el procesamiento de los criados de Calisto es injusto e ilegal porque se les ejecutó públicamente sin juicio previo y sin darles la oportunidad de que tuvieran una muerte cristiana (2015: 63).

65.- En contraste con su coetánea telefílmica, la Melibea literaria conjetura situaciones distintas: "¿Quién sabe, si él, con voluntad de venir al prometido plazo en la forma que los tales mancebos a las tales horas suelen andar, fue topado de los alguaziles noturnos e sin le conocer le han acometido, el qual por se defender los offendió o es dellos offendido? ¿○ si por caso los ladradores perros con sus crueles dientes, que ninguna differencia saben hazer ni acatamiento de personas, le ayan mordido? ¿O si ha caydo en alguna callada o hoyo, donde algún daño le viniesse?» (Rojas 1499: 125). 
drado lo atenúa de algún modo en el momento en que Melibea invita al caballero a bajar precavidamente para después retirarse hacia los árboles en donde no estarán más expuestos. Una vez ahí, Calisto hace un ritual cortesano en el que se hinca ante su amada para expresarle su deseo de una forma bastante sutil y disculparse con ella porque pondrá sus manos sobre su cuerpo. Inmediatamente, la joven le corresponde con un beso, dando a entender que iniciarán su primera relación sexual sin permitir que el televidente u otros personajes en la recreación sean testigos del acto. ${ }^{66}$ De tal forma, el volumen de la música sublime que acompaña la secuencia empieza a aumentar, mientras que la cámara hace un travelling hacia arriba perdiéndose entre las hojas de los árboles.

En la siguiente escena diurna, se observa a Calisto emitir un soliloquio en su alcoba sobre el encuentro que tuvo con Melibea. No obstante, su felicidad se desvanece al poco tiempo en que recuerda las consecuencias que traerán las muertes de Pármeno y Sempronio ahora que todo el mundo sabe de lo ocurrido, tales como la perdición de su fama y su patrimonio. En contraste con el protagonista literario, el telefílmico parece mucho más decidido a seguir dando rienda suelta a su pasión, sobre todo porque el director no incluyó gran parte del diálogo en que el personaje rojano planea fingir cobardemente que estuvo ausente de la ciudad cuando el cruel juez mandó a ejecutar a sus criados. Si bien con dicha omisión el televidente no llega a saber por qué a Calisto le parecen injustas dichas muertes ni los nexos que este hombre tuvo alguna vez con su familia, su actitud resulta en cierta parte semejante con la que Melibea muestra en el hipotexto. Es decir, la de ejercer el libre albedrío en sus acciones, aunque evidentemente no al mismo nivel que ella. A mi juicio, esto se debe a que Guerrero Zamora le dio una segunda oportunidad a este personaje masculino para dejar su lado paródico y así convertirlo, como se verá más adelante, en un héroe romántico en el final de la miniserie. ${ }^{67}$

El tercer evento es el plan que Areúsa y Elicia traman junto con Centurio para vengar la muerte de la vieja matando a Calisto. Para ello, el director añadió nuevas escenas a la trama celestinesca cuya única función es ofrecer más detalles del mundo hampesco. Una de ellas es la que ocurre en la taberna cuando Maribañez, otra de las rameras al servicio de Tripa en brazo, recibe a las protegidas de Celestina con un pésame. ${ }^{68}$ Una vez instaladas, Areúsa procede a denostar cómicamente a su rufián ante los presentes, chantajeándolo con dejarlo con hambre, si no la ayuda

66.- El tratamiento sutil que Guerrero Zamora da a esta escena difiere enormemente con lo que ocurre en el hipotexto, ya que a Calisto le excita que haya testigos de su 'gloria', en este caso Lucrecia, Sosia y Tristán que escuchan el retozar de la pareja (128-9).

67.- Los críticos Severin y Russell opinan que Calisto abandona la parodia en la obra hasta el auto XIV en el que se da la primera relación sexual con Melibea (1987: 29; 2001: 59).

68.- En La Tercera Celestina (1542) de Sancho de Muñón, Maribañez es la sirvienta de Eugenia, madre de la protagonista Roselia, y vecina de la alcahueta. 
en ese momento en que más lo necesita. Sin poder hacer alarde de su valentía, este, avergonzado, sale apresuradamente del lugar. Acto seguido, la prostituta le pide el favor a Parrada, el tabernero, de que cuando vea a Sosia le diga que se pase presto por la casa de la alcahueta para hacerle saber la supuesta última voluntad de su amigo Pármeno.

Después de que Areúsa logra seducir en otra secuencia al escudero de Calisto y sacarle la información sobre el próximo encuentro que tendrá su amo con Melibea, esta se dirige con Elicia a casa de Centurio para solicitarle que lleve a cabo su plan de venganza. En ese sitio, tras recibir varios insultos de la prostituta que le llena el bolso de dinero, el rufián accede finalmente a matar al caballero esa misma noche por las afueras del huerto y con ello poner fin a los negocios de amores causantes de tantas tragedias. Lo más irónico de esta escena es el hecho de que ambas prostitutas telefílmicas, a diferencia de sus coetáneas literarias, saben perfectamente que Centurio se ha comportado como un hombre cobarde desde el acto II, aunque finja ser verbalmente un héroe ante ellas. A mi parecer, Areúsa es tan asusta como para ignorar este detalle, de tal manera, ha recurrido a su rufián porque probablemente presiente que alguno de los compinches de este hará el trabajo sucio en vez de él.

Una vez que las prostitutas se retiran del lugar sin importarles la clase de muerte que supuestamente Centurio le dará a Calisto, el malandrín camina rápidamente hacia el salón donde Traso ha estado todo ese tiempo escuchando su conversación. Como escena añadida a la trama celestinesca, Guerrero Zamora muestra al primero chantajear a su aliado con seguir restregándole por las narices que gracias a él sigue vivo, si no se hace cargo del plan de Areúsa. Traso, irritado de escuchar estas palabras por enésima vez, acepta la demanda de su cómplice de crímenes para saldar por todas la gran deuda que tiene con él. Así, cuando dan las doce de la noche, este espadachín y Tripa en brazo llegan armados a la calle del Vicario, por las tapias del huerto de Pleberio, en donde se encuentran tanto Sosia como Tristán esperando a que su amo termine su cita con Melibea.

Entre tanto, el encuentro entre los jóvenes nobles se representa nuevamente de manera sublime con música renacentista acompañada de planos medios cortos. En contraste con la forma en que se comportan los protagonistas del texto fuente en ese momento, los de esta recreación intercambian palabras dulces y realizan una danza de amor que parece respetar los códigos cortesanos. Ello se debe principalmente a que el director eliminó el comentario famoso del Calisto literario en el que se expresa vulgarmente antes de poseer a Melibea: "Señora, el que quiere comer el aue, quita primero las plumas» (Rojas 1499: 197). De la misma manera, a que no permitió que Lucrecia estuviera presente en ese momento, ni exhibiera la 
conducta voyerista que la caracteriza en el hipotexto, sobre todo cuando su ama está teniendo relaciones sexuales con el joven. ${ }^{69}$

En cuanto a este tema que fácilmente se habría tratado en el cine del destape, el director no buscó desarrollarlo en su recreación pensada para la hora de mayor audiencia de TVE-1 ni siquiera dar a entender sutilmente que en la última cita la pareja tendría relaciones. Por el contrario, para esta secuencia prefirió dar prioridad a la parte trágica de la trama, pues añadió de su cosecha un diálogo en que Calisto se pregunta en voz alta cómo irán a acabar sus amores, lo cual provoca la angustia de Melibea. A mi parecer, las palabras del joven no son para nada un accesorio en ese momento, sino son más bien simbólicas. Es decir, estas sirven como una premonición de las tristes muertes que están por ocurrir.

Después de que la doncella tranquiliza a su caballero con sus dulces palabras, se escucha pelear a los rufianes con los escuderos a las afueras del huerto. Calisto, alarmado, decide ir en su auxilio, ya que teme que los maten por su juventud e inexperiencia con las armas. Sin hacer caso de las advertencias de Melibea, de no acudir desarmado, este sube precipitadamente el muro y, una vez en lo alto, saca su espada para ahuyentar a los criminales que ya tienen acorralados a sus hombres. Sin embargo, poco después se observa en cámara lenta al joven noble caer al vacío al mismo tiempo que se escucha música trágica.

A mi juicio, tales efectos tienen un propósito contrario al de acentuar el drama en esta escena. Esto es el de acartonar e, incluso, ridiculizar la caída de Calisto desde el momento en que parece ser un acto deliberado (Villalobos Graillet 2016: 398), aunque también resultado del mismo atolondramiento que el telespectador ya había visto en él en una escena anterior. Si bien dicho comportamiento formaría parte de la cualidad paródica del joven que, de acuerdo con Lacarra, mantiene hasta su muerte (1989: 18), Guerrero Zamora hace que su personaje supere inmediatamente esta contradicción en su manera de actuar al permitir que diga unas palabras de despedida antes de morir. A diferencia de lo que ocurre en la obra de partida, cuando los rufianes huyen tras ver al noble fatalmente herido, Sosia se encarga de llamar a los alguaciles para que den castigo a estos matadores. Mientras tanto, Tristán escucha atentamente la encomienda que su amo agonizante está por dejarle. Esta se refiere a que mire "por que estos amores no sean escarnio para [su] señora» $y$, asimismo, a que vele «por la buena memoria de una pasión que más debe ser llorada que ofendida [y que] tan triste fin tuvo».

69.- He aquí un ejemplo de ello: «LUCRECIA.- (Aparte.) Mala landre me mate, si más los escucho. ¿Vida es esta? ¡Que me esté yo deshaziendo de dentera y ella esquiuándose porque la rueguen! Ya, ya apaziguado es el ruydo: no ouieron menester despartidores. Pero también me lo haría yo, si estos necios de sus criados me fablassen entre día; pero esperan que los tengo de yr a buscar» (Rojas 1499: 197). 
Según la interpretación que hago de este último momento que no aparece en el texto de Rojas, el director se empeñó en convertir a Calisto en un héroe romántico. Esto es porque las palabras del joven denotan el deseo de que sus amores con Melibea triunfen sobre las convenciones sociales, religiosas y legales. Por esa razón, en su súplica da a entender que no se les castigue por haber mantenido una relación clandestina que llevó a la joven a perder su fama, sino por el contrario, que se les vea como personas que se dejaron llevar por una pasión verdadera. De tal manera, cuando su amo muere, los criados no retiran presto su cuerpo inerte por miedo a represalias. ${ }^{70}$ En cambio, me parece que si Tristán lo acerca a la entrada del palacete de Pleberio es para que el pueblo ratifique esa verdad $y$, a su vez, reconozca que el único crimen que ahí se ha cometido es la muerte del joven noble a causa de un ajuste de cuentas. Sin embargo, una nueva tragedia va a acaparar la atención de la multitud presente.

Melibea, conmocionada por la muerte de su amado, se encierra en la torre de su casa para que nadie impida su suicidio. Antes de que ello ocurra, tiene la oportunidad de dirigir unas palabras a Pleberio y Alisa que se encuentran detrás de la puerta junto con su criada. A modo de confesión, la joven comenta, sin hacer ninguna referencia a la intercesión de una alcahueta, llámese Celestina o Lucrecia, que perdió la virginidad con Calisto por elección propia, pero, sobre todo, por el amor que sentía por él. Así, ruega a sus padres que no la culpen por este yerro y, en cambio, consientan cumplir con su última voluntad de que las sepulturas de ambos sean juntas. Acto seguido, la doncella se arroja desde lo alto de la torre obligada a seguir por el camino de la muerte a quien considera su esposo. Este último momento es representado enteramente por primera vez en la historia de las recreaciones audiovisuales basadas en $L C$, aunque aún de forma sutil. Para tal fin, el director empleó su ya conocida cámara lenta, un travelling del cuerpo de Melibea que lleva un vestido de semblante nupcial, así como un efecto sonoro de viento que acompaña esta imagen trágica. ${ }^{71}$

El hecho de que la hija de Pleberio caiga muerta junto al cadáver de su amado no es mera coincidencia en la trama. A mi modo de ver, Guerrero Zamora quiso que este personaje consiguiera, al igual que Calisto, la cualidad de heroína romántica hacia el final de la miniserie. A saber, la protagonista telefílmica se suicida porque no puede gozar más de una relación basada en amor y no en las convenciones sociales de parentesco o de alto origen que sus padres traen a colación en la escena en que acuerdan con casarla pronto y en la que también se da a entender, por el precedente de

70.- A diferencia de esta acción, en la obra Sosia y Tristán se llevan presto el cuerpo de Calisto «donde no padezca su honra detrimento» (Rojas 1499: 203).

71.- Curiosamente, en las recreaciones de cine y televisión anteriores a la de 1983 se retrata a Melibea portando un vestido blanco como si se tratase de una novia. 
la condición conversa del caballero, que este quedaría descartado como posible candidato. ${ }^{72}$ En vista del obstáculo racial que el director plantea en su recreación, Melibea accedió a cumplir con la propuesta de Lucrecia, de unirse a Calisto por una vía alternativa al casamiento tradicional. ${ }^{73}$ Por tal motivo, para mí, el momento en que muere simboliza la lealtad que ella tiene hacia la convicción de elegir su propia pareja nupcial y de disfrutar de ese amor más allá de toda imposición religiosa-social.

En la última secuencia nocturna de la miniserie, los padres de la joven bajan presto con Lucrecia a la calle en donde se encuentran con una multitud rodeando a los cuerpos de los infortunados amantes. Inmediatamente, Pleberio demanda al pueblo conmovido, incluyendo a los criados del joven noble, que se retire del lugar por respeto al dolor de su familia. Una vez solos, el teleasta muestra, por un lado, con varios primeros planos al padre prorrumpir en dolorosa protesta contra el destino trágico de su hija a causa del amor, la cual resulta breve si se le compara con la del texto fuente. Y, por otro, con un plano a detalle a Alisa unir entre sus manos la sangre de Calisto con la de Melibea.

En otro trabajo había calificado esta escena de insólita porque, además de que no que ocurre en el hipotexto, el tema de la honra no parece importar en esos momentos (Villalobos Graillet 2016: 402). No obstante, este aspecto tiene mayor sentido si se tiene en cuenta que en el Medioevo Tardío cuando trascendía públicamente un matrimonio clandestino como el que la protagonista cree haber efectuado en esta recreación, "la pérdida de la virginidad no era tan grave» (Iglesias 2014: 474). Por tal razón, al final se observa tanto a Pleberio como a su esposa no tener otra opción sino la de validar dicha unión en memoria de su hija. A mi juicio, con esta acción se aminorarían las complicaciones judiciales que se cree que los coetáneos literarios de ambos personajes habrían sufrido tras el suicidio de la joven. ${ }^{74}$

El último episodio del hipertexto concluye con un movimiento de grúa que pasa del close-up de Pleberio sosteniendo el cadáver de Melibea hasta el plano general en picado de los personajes sobrevivientes sacudidos por sus sollozos. La iluminación nocturna, el efecto sonoro de viento y la posterior música de órgano que Guerrero Zamora escogió son acertados para acentuar la desolación de este grupo trágicamente tallado. Ahora bien, toca el turno de preguntarse si con tal final el director cumplió la intención que en principio se había planteado desarrollar en su miniserie. En mi

72.- Rodríguez Puértolas considera que Calisto es un ejemplo de «una de tantas familias de origen judío caídas en la desgracia y en el desdén sociales» (1972: 216).

73.- Las últimas palabras de la joven en la miniserie comprueban que entre ellos hubo un tipo de unión clandestina similar a la de Polandria y Felides en la Segunda Celestina, aunque no con el mismo final trágico: «[...] pero una esposa debe seguir a su señor. ¡Que Dios lo acompañe! A él le entrego mi alma».

74.- Al respecto, consúltese el trabajo de Iglesias (2015: 68-9). 
opinión, las circunstancias que rodean la muerte de los amantes telefílmicos son incongruentes con el afán moral que el teleasta interpretó en la obra de Rojas. Es decir, de aquel que condena los efectos destructivos de las pasiones, así como de las personas (los 'lisonjeros', 'criados' y 'falsas alcahuetas') que incitan la lujuria en los protagonistas. Esto se debe principalmente a la interferencia intertextual con la obra de Feliciano de Silva que hice alusión anteriormente, pues, tal como ocurre con Polandria, la hija de Pleberio en la miniserie piensa en la posibilidad de desposarse con su amado gracias al consejo de su criada, aunque con la diferencia de que ello signifique luchar en contra de las diferencias raciales o religiosas que impiden que sea socialmente feliz a lado de él.

Como consecuencia, el efecto igualador de la danza macabra del segundo episodio pasa a ser al final de la trama, en vez de una crítica al orden social medieval y al período franquista que destaqué en líneas arriba, un mensaje en que el amor está por encima de todo, incluso de la propia vida. Dicho esto, el realizador no hace perecer a sus protagonistas para que reciban un posible castigo civil y religioso, sino todo lo contrario. Según interpreto las últimas palabras de Calisto, el teleasta tuvo la intención de rendir, a diferencia del autor literario, un homenaje a este amor imposible, por ende, de naturaleza trágica. Teniendo en cuenta esto, las muertes de Celestina, Sempronio y Pármeno no se llegan tampoco a interpretar como un castigo por romper barreras éticas y sociales al haber participado en los negocios de estos amores. En cambio, tales eventos trágicos se representan únicamente para destacar que fueron resultado de la avaricia de estos personajes marginados.

A pesar de haber una inconsistencia entre el propósito inicial de Guerrero Zamora con la conclusión que le da a la trama, considero que a su miniserie no se le debería condenar al olvido por dos motivos. En mi primer lugar, esta es una muestra del esfuerzo del director en ofrecer por primera vez más detalles del mundo celestinesco que las recreaciones de cine y televisión basadas en $L C$ que le preceden. De ahí que haya reelaborado tanto las escenas como los personajes a partir de las conexiones intertextuales que efectúa con otras obras continuadoras de la tradición fundada por Fernando de Rojas. ${ }^{75}$ En segundo, este hipertexto es uno de los pocos ejemplos en la historia del cine español de la supervivencia de un proyecto cinematográfico que logró producirse en TVE casi dos décadas después de haber sido censurado durante la tercera etapa franquista. Por último, si bien desconozco que de haber sido la miniserie «algo menos libre, [habría] logrado una mayor aceptación» ("El último» 1983: 109), de lo que sí estoy seguro es que el teleasta no habría sido infiel a su estética y sello personal

75.- Supongo que lo que Fernández llama en su reseña de la recreación telefílmica de 1983 «errores de todo tipo» (2018: 880) se refiere a las interferencias intertextuales que localicé en este análisis. 
que lo caracterizaron como pionero de los espacios dramáticos y de la televisión de autor.

\section{Bibliografía}

AmiliBiA. "Nuria Torray: 'solamente trabajan los actores que tienen carné del PSOE...' ", $A B C$ (Madrid), 10 oct 1983, p. 83.

-. "'La Celestina' demanda a TVE», ABC (Madrid), 12 oct 1983, p. 91.

ArChivo General de la Administración. Expte. no. 108-65. Caja no. 36.0404, Alcalá de Henares, 1964.

—. Expte. no. 108-66. Caja no. 36.0404, Alcalá de Henares, 1965.

Ardavín Fernández, César (dir.). La Celestina, con la actuación de Julián Mateos, Elisa Ramírez, Amelia de la Torre, Gonzalo Cañas, Antonio Medina, Aro Films, 1969.

Boletín Oficial del Estado, Ministerio de Información y Turismo. "Orden de 9 de febrero de 1963 por la que se aprueban las 'Normas de censura cinematográfica' ", $B O E, 58$, (1963), pp. 3929-3930, <https://www. boe.es/boe/dias/1963/03/08/pdfs/A03929-03930.pdf>. Último acceso 13 feb 2019.

—. "Orden de 19 de agosto de 1964 para el desarrollo de la cinematografía nacional, acordada por la Comisión Delegada de Asuntos Económicos a propuesta del Ministerio de Información y Turismo", BOE, 210, (1964), pp. 11461-11466, <https://www.boe.es/boe/dias/1964/09/01/ pdfs/A11461-11466.pdf>. Último acceso 13 feb 2019.

BotTA, Patricia. «La magia en La Celestina», Dicenda, 14 (1994), pp. 37-69. Bravo Nieto, Antonio. "Guerrero Zamora, Juan», en Diccionario biográfico español XXV, Madrid, Real Academia de la Historia, 2009, p. 80.

Camus, Mario (dir.). Los desastres de la guerra, con la actuación de Sancho Gracia, Francisco Rabal, Bernard Fresson, Mario Pardo, Carlos Larrañaga, Philippe Rouleau, Televisión Española, 1983.

CAÑAS, Gabriela. «Los tres episodios de la serie han costado 200 millones de pesetas", El País, 4 oct 1983, <https://elpais.com/diario/1983/10/04/ radiotv/434070003_850215.html>. Último acceso 13 feb 2019.

CÁrdenas-Rotunno, Anthony J. "Rojas's Celestina and Claudina in Search of a Witch", Hispanic Review, 69.3 (2001), pp. 277-299.

CASESMEIRO ROGER, Jorge. "Imprescindible Guerrero Zamora», El Imparcial, 10 dic 2017, <https:/www.elimparcial.es/noticia/184522/opinion/ imprescindible-guerrero-zamora.html>. Último acceso 13 feb 2019. 
Corbalán, Pablo. "Se anuncia La Celestina», ABC (Madrid), 10 oct 1981, p. 93.

—. "Celestina ataca», $A B C$ (Madrid), 12 oct 1981, p. 92.

CóRdoba DE la Llave, Ricardo. "Violencia cotidiana en Castilla a fines de la Edad Media", en Conflictos sociales, políticos e intelectuales en la España de los siglos XIV y XV: XIV Semana de Estudios Medievales, Nájera, 4 - 8 de agosto de 2003, ed. José Ignacio de la Iglesia Duarte, Logroño, Instituto de Estudios Riojanos, 2004, pp. 393-444.

Crouzet-PAVAN, Élisabeth. "Violence, société et pouvoir à Vennise (XIVexve siècles): forme et evolution de rituals urbains", Mélanges de l'école française de Rome, 96.2 (1984), pp. 903-936.

Deyermond, Alan. «Hilado-Cordón-Cadena: Symbolic Equivalence in $\mathrm{La}$ Celestina», Celestinesca, 1.1 (1977), pp. 6-12.

Diego, Patricia. La ficción en la pequeña pantalla. Cincuenta años de series en España, Pamplona, EUNSA, 2010.

"El último capítulo de La Celestina», ABC (Madrid), 20 oct 1983, p. 109.

«Entrevista personal a Alejandra Torray», 9 noviembre 2018, Madrid, España.

FERNÁNDEZ, Enrique. "La picaresca y la celestinesca en las pantallas españolas de los sesenta a los ochenta", eHumanista, 38 (2018), pp. 873-889.

Fulier, Eduardo (dir.). La Celestina, con la actuación de Francisco Guijar, Lolita Herrera, Julio Muñoz, Francisco Portes, Lola Gaos, Televisión Española (Teatro de siempre), 1967.

GarcíA, Juan Ignacio. "Nuria Torray, Melibea emprende el vuelo», $A B C$ (Madrid), 4 oct 1983, p. 97.

García de Castro, Mario. La ficción televisiva popular. Una evolución de las series de televisión española, Barcelona, Gedisa, 2002.

García Garzón, Juan I. "Juan Guerrero Zamora defiende su 'Celestina'», $A B C$ (Madrid), 18 oct 1983, p. 91.

Gimber, Arno. "Los rufianes de la primera 'Celestina': observaciones acerca de una influencia literaria», Celestinesca, 16.2 (1992), pp. 63-76.

Gómez BeRmúdeZ DE CASTRO, Ramiro. La producción cinematográfica española de la Transición a la Democracia, Bilbao, Ediciones Mensajero, 1989.

GuARINOs, Virginia. "El teatro en TVE durante la transición (1975-1982). Un panorama con freno y marcha atrás», en Televisión y literatura en la España de la transición (1973-1982), ed. Antonio Ansón Anadón, Zaragoza, Institución 'Fernando el Católico', 2010, pp. 97-118.

Guerrero Zamora, Juan. Historia del teatro contemporáneo, Barcelona, Juan Flors, 1961-1967.

- (dir.). Fuenteovejuna, con la actuación de Nuria Torray, Manuel Dicenta, Miguel Ángel, Antonio Puga, Marcela Yurfa, Estanis González, Televisión Española y RAI, 1970. 
Guerrero Zamora, Juan (dir.). Los mitos, con la actuación de Nuria Torray, Rosa Fontana, Rafael Arcos, Modesto Blanch, María Jesús Hoyos, Andrés Mejuto, Televisión Española, 1979.

—. "Puntualizaciones de Juan Guerrero Zamora», El País, 09 feb 1980, $<$ https://elpais.com/diario/1980/02/09/opinion/318898807_850215. html>. Último acceso 13 feb 2019.

- (dir.). La Celestina, con la actuación de Miguel Ayones, José Caride, Gemma Cuervo, José Lara, Nuria Torray, Toni Soler, Televisión Española, 1983.

Guerrero Zamora, Juan. «Réplica sobre 'La Celestina'», El País, 25 oct 1983, $<$ https://elpais.com/diario/1983/10/25/opinion/435884410_850215. html>. Último acceso 13 feb 2019.

- " "Teatro, televisión, cultura y otras manzanas (con o sin gusano) en la misma cesta», Aldaba, 8 (1987), pp. 23-36.

«Guerrero Zamora: Los mitos, La Celestina», ABC (Madrid), 11 nov 1981, p. 93.

Haro TeCglen, Eduardo. "Celestina': la ambientación, protagonista", El País, 15 oct 1983, <https://elpais.com/diario/1983/10/15/radiotv/435020404_850215.html>. Último acceso 13 feb 2019.

IGLESIAS, Yolanda. «La prostitución en La Celestina: estudio histórico-literario», eHumanista, 19 (2011), pp. 193-208.

- - "Aspectos legales y sociales del matrimonio: un acercamiento desde La Celestina y sus continuadores», Revista Canadiense de Estudios Hispánicos, 38.3 (2014), pp. 467-484.

-. "Implicaciones legales de las seis muertes en La Celestina: un acercamiento histórico-literario", Romance Quarterly, 62.2 (2015), pp. 59-70.

-. "Celestina in Film and Television", en A Companion to Celestina, ed. Enrique Fernández, Leiden, Brill, 2017, pp. 383-402.

«Inspección técnica para La Celestina», ABC (Madrid), 27 nov 1981, p. 109. "Juan Guerrero Zamora y la serie de nunca acabar. La estafa de La Celestina», Diario 16, 15 nov 1982, p. 44.

Lacarra Lanz, María Eugenia. «La parodia de la ficción sentimental en $\mathrm{La}$ Celestina», Celestinesca, 13.1 (1989), pp. 11-29.

"La Celestina de Guerrero Zamora, para este invierno", $A B C$ (Madrid), 14 oct 1982, p. 101.

LADERO QuesAda, Miguel-Ángel. "Aristócratas y marginales: aspectos de la sociedad castellana en La Celestina", Espacio, tiempo y forma. Serie III, Historia medieval, 3 (1990), pp. 95-120.

Lizzani, Carlo (dir.). Celestina P...R..., con la actuación de Assia Norris, Venantino Venantini, Beb Loncar, Rafaella Carrà, Marilù Tolo, Aston Films, 1965.

López-Ríos, Santiago. "Señor, por holgar con el cordón no querrás gozar de Melibea': la parodia del culto a las reliquias en la Celestina», MLN, 127.2 (2012), pp. 190-207. 
LÓPEz-Ríos, Santiago. "La Celestina en el franquismo: en torno a una frustrada película de José Luis Sáenz de Heredia», Acta Literaria, 49 (2014), pp. 139-157.

MuÑón, Sancho de. La tercera Celestina: Tragicomedia de Lisandro y Roselia, obra de pasatiempo y recreación [1542], ed. Joaquín López Barbadillo, Madrid, Akal, 1977.

Orozco Díaz, Emilio. "La Celestina: hipótesis para una interpretación», Ínsula, 124 (1957), pp.1-10.

Palacio, Manuel. Historia de la televisión en España, Barcelona, Gedisa, 2001.

Palacio, Manuel. «Los intelectuales y la imagen de la televisión cultural», en Televisión y literatura en la España de la transición (1973-1982), ed. Antonio Ansón Anadón, Zaragoza, Institución 'Fernando el Católico', 2010, pp. 11-24.

- La televisión durante la Transición española, Madrid, Cátedra, 2012.

Peña Ardid, Carmen. «Los mitos/Un mito llamado...», en Televisión y literatura en la España de la transición (1973-1982), ed. Antonio Ansón Anadón, Zaragoza, Institución 'Fernando el Católico', 2010, pp. 357-362.

Pérez Ornia, José Ramón. La televisión y los socialistas. Actividades del PSOE respecto a TVE durante la Transición (1976-1981), Disertación, Universidad Complutense de Madrid, 1988.

Pujol, Rafael, (dir.). La Celestina, Radio Cadena España, 1981.

Rodrigo-Estevan, María Luz. "Deporte, juego y espectáculo en la España Medieval: Aragón, siglos XIII-XV», en Ensayos sobre deportes. Perspectivas sociales e históricas, eds. Luis Cantarero Abad y Ricardo Ávila Palafox, Zaragoza, CUCSH, 2007, pp. 37-88.

Rodríguez Cascante, Francisco. "La seducción de Celestina y el honor de Melibea en la recepción de Feliciano de Silva", Celestinesca, 25.1-2 (2001), pp. 21-46.

Rodríguez Puértolas, Julio. "El linaje de Calisto», en De la Edad Media a la edad conflictiva: estudios de literatura española, ed. por Julio Rodríguez Puértolas, Madrid, Gredos, 1972, pp. 209-216.

—. "La Celestina y Guerrero Zamora», El País, 6 nov 1983, <https://elpais. com/diario/1983/11/06/opinion/436921208_850215.html>. Último acceso 13 feb 2019.

R. BARCiA, José. "La Celestina, en Televisión Española», El País, 20 oct 1983, $<$ https://elpais.com/diario/1983/10/20/opinion/435452404_850215. html>. Último acceso 13 feb 2019.

RojAs, Fernando de. La Celestina [1499], ed. Julio Cejador y Frauca, Madrid, Ediciones 'La Lectura' (Clásicos Castellanos, vol. 20 y 23), 1913.

Rubia Barcuil, José. "Usurpación sobre La Celestina», El País, 17 nov 1983, $<$ https://elpais.com/diario/1983/11/17/opinion/437871609_850215. html>. Último acceso 13 feb 2019. 
Russell, Peter E. «Introducción», en La Celestina. Comedia o Tragicomedia de Calisto y Melibea, ed. Peter E. Russell, Barcelona, Castalia, 2001, pp. 11-165.

Salazar y Torres, Agustín et. al. El encanto es la hermosura y el hechizo sin hechizo- La segunda Celestina [1654], ed. Thomas A. O'Conner, Tempe, MRTS, 1994.

SeVERIN, Dorothy Sherman. «Introducción», en La Celestina, ed. Dorothy S. Severin, Madrid, Cátedra Letras Hispánicas, 1987, pp. 3-38

Silva, Feliciano de. Segunda Celestina[1534], ed. Consolación Baranda, Madrid, Cátedra, 1988.

Snow, Joseph T. «Four Celestina Productions», Celestinesca, 7.2 (1983), pp. 29-34.

"Una digna Celestina», $A B C$ (Madrid), 06 oct 1983, p. 102.

Vera, Gerardo Vera (dir.). La Celestina, con la actuación de Penélope Cruz, Terele Pávez, Diego Botto, Jordi Mollà, Nacho Novo, Lola Films, 1996.

Villalobos Graillet, José Eduardo. «Análisis de las muertes en las adaptaciones de cine y televisión de La Celestina: convergencias y discrepancias con el texto original», eHumanista, 34 (2016), pp. 387-406.

Wheeler, Duncan. Golden Age Drama in Contemporary Spain. The Comedia on Page, Stage and Screen, Cardiff, University of Wales Press, 2012.

YALE. «La Celestina, al cine», Pueblo (Madrid), 2 ago 1965, s.p. 


\section{Anexo 1: Ficha técnica}

\section{La Celestina (proyecto autocensurado de 1965)}

Equipo técnico y artístico

Director:

Ayudante de dirección

Secretaria de rodaje:

Guion:

Dir. Gral. de producción

Jefe de producción:

Ayudante de producción:

Regidor:

Operador jefe:

2do. operador:

Ayudante de cámara:

Foto fija:

Decorador:

Ayudante:

Montador:

Ayudante de montaje:

Maquillador:

Ayudante maquillador:

Música:

Actores:
Juan Guerrero Zamora

Luis Ligero

Carmen Salas

Juan Guerrero Zamora

Jesús Ma. López-Patiño

Juan Zaro Mateos

José Zaro Mateos

Luis Vázquez

Antonio Macasoli

Ricardo Andreu

Fernando Perrote

Simón López

Sigfredo Burman

Wolfgang Burman

Antonio Ramírez

Enrique Agulló

José Luis Ramírez

Miguel Sesé

Cristóbal Halfter

Luis Dávila (Calisto), Analía Gadé (Melibea), Margarita Xirgu (Celestina), José Rubio (Pármeno), José Calvo (Sempronio), Paula Marel (Areúsa), Ma. Luisa Ponte (Elicia), Mercedes Barranco (Lucrecia), Venancio Muro (Sosia), Agustín González (Crito), Ángel Picazo (Pleberio), Vicky Lagos (Quincia), Fernando Sancho (Traso), José Sepúlveda (Tabernero), Juan Diego (Tristán), Maruga Ga. Alonso (Alisa), Antonio Fernández (Tripa en brazo), Carlos Ballesteros (Estudiante 1). 
Productora:

Largometraje:

Estudios de rodaje:

Exteriores:

Presupuesto:

Attrezo:

Otros lugares y gente:
Cooperativa CITA Films

Blanco y Negro

Sevilla Films (28 días de rodaje)

Salamanca y Provincia de Madrid (60 días de rodaje)

11.302.012 pesetas

Salamanca (22 días de alquiler de naturales), plaza de toros, caída, caballo, pelea. Cueva de Celestina, taberna, torre.

sala palacio justicia (gentes sala de justicia), casa velatorio, pórtico iglesia, puertas universidad, calles mascarada afuera, campo, campo arroyo, tapias, plaza de toros, taberna mísera, casa de Centurio. Gente de pueblo con antorchas, faroles, ahorcado, material para la cueva de Celestina.

\section{Anexo 2: Ficha técnica \\ La Celestina (1983) \\ Equipo técnico y artístico}

Director:

Ayuda de dirección:

Secretarias de dirección:

Guion:

Productores:

Ayudantes de producción:

Regidor:

Montador:

Ayudante de cámaras:
Juan Guerrero Zamora

May Velasco, Patricia Ferreira y Miguel Martí Larroya

Consuelo Alfaya y Mayte de la Cruz

Juan Guerrero Zamora

José Aranda, Alfonso García y Manuel Sánchez

Ramón Sanz, Ángel Parrondo, Pedro Sopeña, Ricardo Rodríguez, José F. Gutiérrez, Pilar Tabares y M. Ángeles Sánz

Ángel Sevillano

Alfonso Santacana

Ramiro Sabell y Saturnino Pita 
Directores de fotografía: Rafael Casenave, Rafael Pacheco y Alejandro Ulloa

Foto fija:

Rafael Onieva, Luis Villanueva, Antonio Pérez Barguilla

Ayudantes de sonido: $\quad$ Manuel Ferreiro, Manuel Barroso, Óscar Danés, César de la Puente

Equipo eléctrico:

Casimiro Delgra, Antonio Rodríguez, Teodoro García Muñoz, Vicente Lozano, José Sacristán, José Sánchez Martín, Francisco Jurado, Enrique Porras, Agustín Arellano, Luis Saavedra, José Martín Ocaña, Tomás Roa, Francisco Ocaña, Juan Pompas y Gregorio Alonso

Efectos especiales:

Especialista: José Ma. González y José Ma. Martínez Pedro Palomo

Maestro de armas:

J.L. Chinchilla

Asistencias de rodaje:

Ayudante de montaje:

Manuel Puertas, Lorenzo León, Vicente Suárez y Antonio Chisvert

Grúas:

Pilar Millán

Música:

Vestuario:

Decoración:

Equipo de decoración:

Decorados:

Figurines:

Operadores:

Sonido:

Maquillaje:

Equipo de maquillaje:

Peluquería:

Valero

Alejandro Massó

Cornejo

Miguel Díaz Orts y Pablo Gago

Luciano Arroyo, Carmen Martín Pérez, Juan Forcada, Claudio Torres, Vicente Garrido, Ricardo San Julián, Urbano Sánchez, Ángel Martín, Victoriano Yáñez y Antonio Jaramillo

Prosper

María Ángeles Moreno

Ramón F. Prestamero y Ricardo Andreu

Julián del Santo

Fernando Martínez y Manuel Novoa

Mercedes Gómez Escudero, Esther Sánchez Lallana y J.L. Farsac

Carmen Ruiz e Inés González

Equipo de peluquería:

Consuelo Zahonero y Mercedes Guillot 
Equipo de vestuario:

Actores:

Otros actores:

Estudios de rodaje:

Estudios de sonorización:

Laboratorios:

Productora:

Locaciones:

Presupuesto:

Estreno:

Canal y hora:

Duración:
Juan Chamizo, Marina Rodríguez, Melquiades Álvarez, Margarita Curieses, Tomasa Pintado, Raúl Cazorla y Martín Díaz

Miguel Ayones (Calisto), José Caride (Sempronio), Gemma Cuervo (Elicia) José Lara (Pármeno), Cándida Losada (Alisa), Lorenzo Ramírez (Centurio), José Segura (Traso), Toni Soler (Celestina), Tina Sainz (Areúsa), Nuria Torray (Melibea), Luis Prendes/ William Layton (Pleberio), Lola Santoyo (Lucrecia), Rafael Cabarcos (Sosia), Francisco Sánchez Grajera (Tristán), Fernando Sotuela (Crito)

Pilar Cansino, Margarita Calahorra, Encarna Chimeno, María José Fernández, Francisco Lahoz, Francisco Bernal, Miguel Ángel, Roberto Cruz, Mario Abad, Luis Baringo, José M. Carrero, José E. Camacho, Ángel Egido, Fernando Baeza, Carlos Alemán, Miguel Godoy, Alfonso Vallejo, Javier Zanca, Emilio Fuentes, Paul Benson, Mario Siles, Jorge Grosso, E. Mellado, A. Besco, José Lahoz TVE Prado del Rey

Cinearte

Riera

TVE en colaboración con Films77

Monasterios de Santes Creus (Tarragona) y San Juan de Duero (Soria), San Polo (Soria), Castillo de Manzanares El Real, Soria capital y ciudad monumental de Cáceres

200.000.000 de pesetas (aprox.)

4, 11 y 18 de octubre de 1983

TVE-1, 10:05-11:30 p.m.

171 minutos 
